\title{
A Study of Interactions Between Thrust and Strike-slip Faults
}

\author{
Jeng-Cheng Wang ${ }^{1, *}$, Chiou-Fen Shieh ${ }^{2}$, and Jeen-Hwa Wang ${ }^{3}$ \\ ${ }^{1}$ Department of Applied Geoinformatics, Chia-Nan University of Pharmacy and Science, Tainan, Taiwan, R.O.C. \\ ${ }^{2}$ Institute of Seismology, National Chung Cheng University, Chiayi, Taiwan, R.O.C. \\ ${ }^{3}$ Institute of Earth Sciences, Academia Sinica, Taipei, Taiwan, R.O.C.
}

Received 22 June 2012, accepted 8 May 2013

\begin{abstract}
A 3-D finite difference method is applied in this study to investigate a spontaneous rupture within a fault system which includes a primary thrust fault and two strike-slip sub-faults. With the occurrence of a rupture on a fault, the rupture condition follows Coulomb's friction law wherein the stress-slip obeys the slip-weakening fracture criteria. To overcome the geometrical complexity of such a system, a finite difference method is encoded in two different coordinate systems; then, the calculated displacements are connected between the two systems using a 2-D interpolation technique. The rupture is initiated at the center of the main fault under the compression of regional tectonic stresses and then propagates to the boundaries whereby the main fault rupture triggers two strike-slip sub-faults. Simulation results suggest that the triggering of two sub-faults is attributed to two primary factors, regional tectonic stresses and the relative distances between the two sub-faults and the main fault.
\end{abstract}

Key words: Finite difference method, Coulomb's friction law, Slip-weakening fracture criteria

Citation: Wang, J. C., C.F. Shieh, and J. H. Wang, 2013: A study of interactions between thrust and strike-slip faults. Terr. Atmos. Ocean. Sci., 24, 809-825, doi: 10.3319/TAO.2013.05.08.02(T)

\section{INTRODUCTION}

The primary fault in a highly complex fault system is usually accompanied by several branch faults. The 1992 Landers earthquake $\left(\mathrm{M}_{\mathrm{w}}\right.$ 7.3), 1998 Antarctic earthquake $\left(M_{w} 8.1\right)$ and 1997 Kagoshima earthquake $\left(M_{w} 6.0\right)$ are all good examples (Kase and Kuge 2001). It is necessary to understand the interactions between these faults when an earthquake occurs. For this purpose, the rupture processes of the main fault and those of the branch faults caused by stress changes induced from the failure of the main fault must be investigated. Meanwhile, the dynamic behavior of a fault system within a short time period, from a few seconds to just tens of seconds, should be inferred from observations. The rupture processes include initiation, propagation, and arrest of ruptures (Aki 1979; Lindh and Boore 1981; Scholz 1990). Entire rupture processes are controlled primarily by physical and geological conditions of the fault system.

Before the 1990s, fault braches were not included in the models used for the studies of dynamic rupture processes (Das and Aki 1977; Miyatake 1980; Day 1982; Mi-

\footnotetext{
* Corresponding author

E-mail: jcwang@mail.chna.edu.tw
}

kumo et al. 1987). But current studies had considered the occurrence of a mainshock and additional stresses which are generated in the source area and its surroundings and, perhaps, trigger subsequent events within branch faults (King and Cocco 2001; Wang and Chen 2001; Wang et al. 2003, 2010; Lin and Stein 2004; Ma et al. 2005; Chan and Stein 2009). Recently, this type of fault interaction, especially for a strike-slip fault system has been widely studied by earth scientists. One of the notable examples is the San Andreas fault in California (Harris and Day 1993; Yamashita and Umeda 1994; Kase and Kuge 1998, 2001). Deffontaines et al. $(1994,1997)$ first pointed out possible interactions between a thrust front and transfer faults in Taiwan.

The stress changes in a source area and its surrounding areas due to a failure of a thrust fault has garnered much attention by seismologists. For example, Ma et al. (1999) studied the spatial stress re-distribution caused by the devastating $1999 \mathrm{M}_{\mathrm{w}}$ 7.6 Chi-Chi earthquake which ruptured along the thrust-type Chelungpu fault. From the focal mechanism of the mainshock and aftershocks of the Chi-Chi earthquake, Mozziconacci et al. (2009) investigated the interaction between the Chelungpu fault and the Sanyi-Puli transfer fault zone (a strike-slip fault zone). Mozziconacci et al. (2013) 
investigated the interaction between the thrust main fault of the $2006 \mathrm{M}_{\mathrm{w}} 6.1$ Taitung earthquake and its strike-slip sub-faults. The geologic map of active faults in Taiwan (Lin et al. 2000) shows several strike-slip faults (from south to north) which are indeed located near respective main thrust faults. For example, in both the northern and southern ends of the Chelungpu fault there are two sub-faults (Lee et al. 2003, 2011). The two sub-faults are not purely strike-slip faulting because both exhibit a dip-faulting component. To simplify the problem, we investigate the interaction between a thrust and two strike-slip faults. In the model, the thrust fault and two strike-slip faults are perpendicular to one another, and the fault geometry is similar to the Chelungpu fault system. This type of study is particularly important for seismically active areas which have a higher population density, are highly industrialized, and have a history of destructive earthquakes. Taiwan is a typical example (Wang 1998, 2008). The 1906 M 7.1 MeiSan earthquakes (cf. Wang 1998), the 1935 M 7 HsinChu-Taichung earthquake (Miyamura 1985; Wang 1998), and the $1999 \mathrm{M}_{\mathrm{w}} 7.6$ Chi-Chi earthquake (Ma et al. 1999) all occurred in highlypopulated areas of Taiwan.

As mentioned earlier, the study of rupture processes in a complex fault system is not only necessary for academic purposes but also for seismic hazard estimates. In this study, a 3-D finite difference method is applied to simulate fault interaction and rupture processes in a model consisting of a main thrust fault linked with two strike-slip faults. The numerical method developed by Wang (2005) will be applied in this study and described in detail below.

\section{METHODOLOGY}

The present model consists of a main thrust fault and two strike-slip faults. Since we are unable to fully elucidate the free surface effects on rupture propagation, the three faults are located $4 \mathrm{~km}$ below the free surface in a homogeneous isotropic medium as shown in Fig. 1a. The main thrust fault (i.e., the central dipping plane in Fig. 1a and named the $\mathrm{M}$-fault hereafter) is defined in the fault coordinates represented by the $\mathrm{X}^{\prime} \mathrm{Y}^{\prime} \mathrm{Z}^{\prime}$ coordinates. For simplification, this system is called the F-coordinate. If the thrust M-fault has a dip angle of $45^{\circ}$, the grid points of the top edges of the two strike-slip type sub-faults are collocated with the grid points of the F-coordinate system and only one coordinate system can be used to describe both $\mathrm{M}$ - and strike-slip faults. Since the M-fault has a dip angle of $30^{\circ}$, the grid points of the top edges of the two strike-slip-type sub-faults cannot be located exactly at the F-coordinate grid points (see Fig. 2, along the $\mathrm{X}^{\prime}$-axis). We need to define a new coordinate system. The two vertical strike-slip sub-faults (i.e., the slashed planes in Fig. 1a) that are perpendicular to the M-fault in the XYZ coordinates are the original coordinates called the O-coordinate. The northern and southern sub-faults (named the $\mathrm{N}$-fault and the S-fault, respectively) are not directly connected to the $\mathrm{M}$-fault, and each separates from the M-fault with $1 \mathrm{~km}$. In the following simulations, the dip angle, $\delta$, of the M-fault is set at $30^{\circ}$ and the strike is $0^{\circ}$ (see Fig. 2) which is almost the average dip angle of numerous major thrusts in Taiwan such as the Chelungpu fault. The fault length and width of the M-fault are 8 and $4 \mathrm{~km}$, respectively in the strike and dip directions. From the relationships of earthquake magnitude versus fault length inferred by Well and Coppersmith (1994), the magnitude of the simulated event is 5.7 because the fault length of the main thrust fault is $8 \mathrm{~km}$.

The two sub-faults have the same length and width, which are 3.46 and $2 \mathrm{~km}$, respectively. The depths of the top edges of the three faults are the same. The initial external regional stresses as shown in Fig. $1 \mathrm{~b}$ are denoted by $\sigma_{X X}$, $\sigma_{Y Y}$, and $\sigma_{Z Z}$. Meanwhile, $\sigma_{X X}$ and $\sigma_{Y Y}$ are the maximum compressive stress and the second largest stress. The angle between the strike of the M-fault and the maximum compressive stress is denoted by $\phi$. Note that $\theta$ and $\phi$ are a pair of complementary angles. While $\sigma_{\mathrm{zz}}$ is the vertical stress normal to the M-fault.

The second-order 3-D finite difference method is applied to simulate ruptures on the M-fault and the transfer of ruptures to the N-and S-faults (Kase and Kuge 1998, 2001). In order to ensure that the calculations are made with highresolution (Olsen et al. 1997; Madariaga et al. 1998) and the $30^{\circ}$-dipping $\mathrm{M}$-fault is completely and exactly located at the grid points, the grid lengths of the M-fault are set to be $\mathrm{dx}^{\prime}=0.2 \mathrm{~km}, \mathrm{dy}^{\prime}=0.2 \mathrm{~km}$, and $\mathrm{dz}^{\prime}=0.1 \mathrm{~km}$ in the F-coordinate. Because the top edges of the two sub-faults must be as high as the main fault, the two sub-faults cannot be located exactly at the grid positions in the F-coordinate (see Fig. 2, along the $\mathrm{X}^{\prime}$-axis), we must let the grid lengths of the sub-faults be $\mathrm{dx}=0.173 \mathrm{~km}, \mathrm{dy}=0.2 \mathrm{~km}$, and $\mathrm{dz}=0.1 \mathrm{~km}$ in the O-coordinate. The physical quantities on the grid points of the M-fault and sub-faults are connected through a 2-D interpolation technique. The numbers of grid points are $41 \times 21$ (along the $\mathrm{Y}^{\prime}$ - and $\mathrm{X}^{\prime}$-axes, respectively) in the F-coordinate for the $\mathrm{M}$-fault and $21 \times 21$ (along the $\mathrm{X}$ - and Z-axes, respectively) in the O-coordinate for the $\mathrm{N}$ and S-faults.

When the rupture is initiated at the center of the Mfault (marked by a star in Figs. 1a and b) at time $t=0$, a decrease in the shear stress, $\sigma$, from the maximum static frictional stress (i.e., the stress drop) results in a displacement wherein the rupture then propagates outward when $t>0$. This would induce stress changes in other non-ruptured areas (including sub-faults). When the shear stress exceeds the maximum static frictional stress in the sub-faults, additional ruptures could also occur. After a rupture occurs, the variation in shear stresses follows slip-weakening fracture criteria (Andrews 1976; Day 1982), as illustrated in Fig. 3, where $\sigma_{0}, \sigma_{s}$, and $\sigma_{d}$ are, respectively, the initial shear 
stress, the maximum static frictional stress, and the dynamic frictional stress; $D_{c}$ is the critical displacement. When $\sigma$ exceeds $\sigma_{s}$, a rupture is initiated and the slip, $d$, increases with time. When $d<D_{c}, \sigma$ decreases linearly with increasing $d$ as displayed by a straight line between $\sigma_{s}$ and $\sigma_{d}$ in Fig. 3 . When $d=D_{c}, \sigma$ is equal to $\sigma_{d}$.

\section{BOUNDARY CONDITIONS}

In a homogeneous and isotropic medium, the wave equation is:

$\rho \ddot{u}_{i}=(\lambda+\mu) u_{j, j i}+\mu u_{i, j j}$ (a)

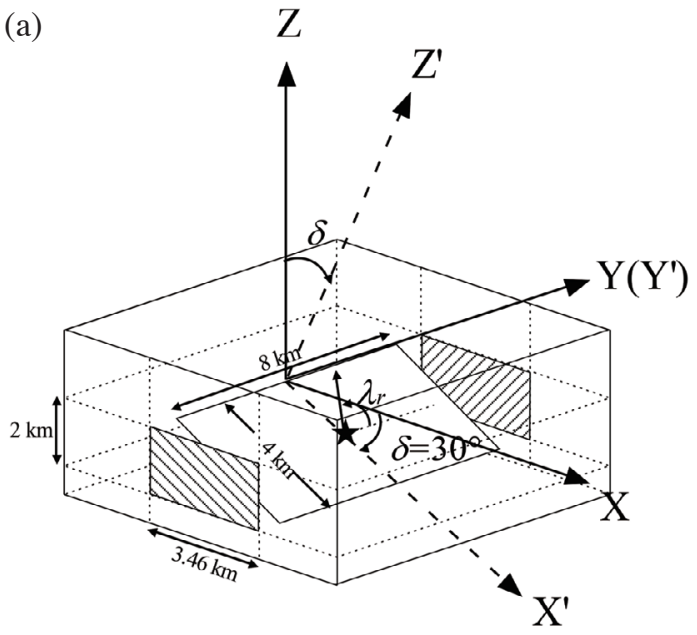

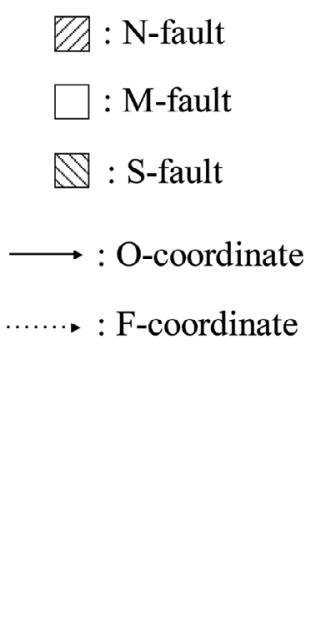

(b)

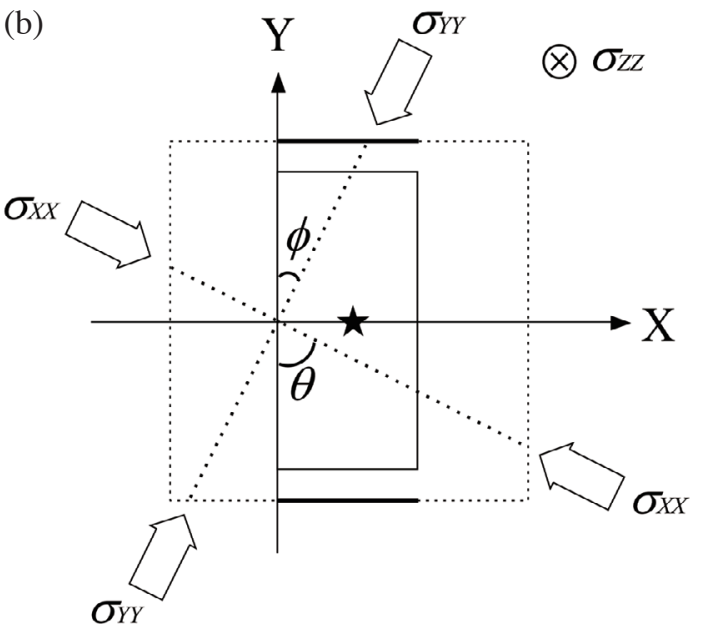

Fig. 1. (a) The fault system is composed of a main thrust (the M-fault) and two strike-slip faults (the N-and S-faults). The faults are $4 \mathrm{~km}$ below the free surface. The main thrust with a strike in the Y-direction and a dip angle of $30^{\circ}$ in the $+X$-direction is on the F-coordinate $\left(X^{\prime} Y^{\prime} Z^{\prime}\right)$, while the other two sub strike-slip faults are on the O-coordinate (XYZ). (b) Plane view of the three faults is given in (a), with the two horizontal compress stresses, i.e., $\sigma_{X X}$ and $\sigma_{Y Y}$, and the vertical stress $\sigma_{Z Z}$.

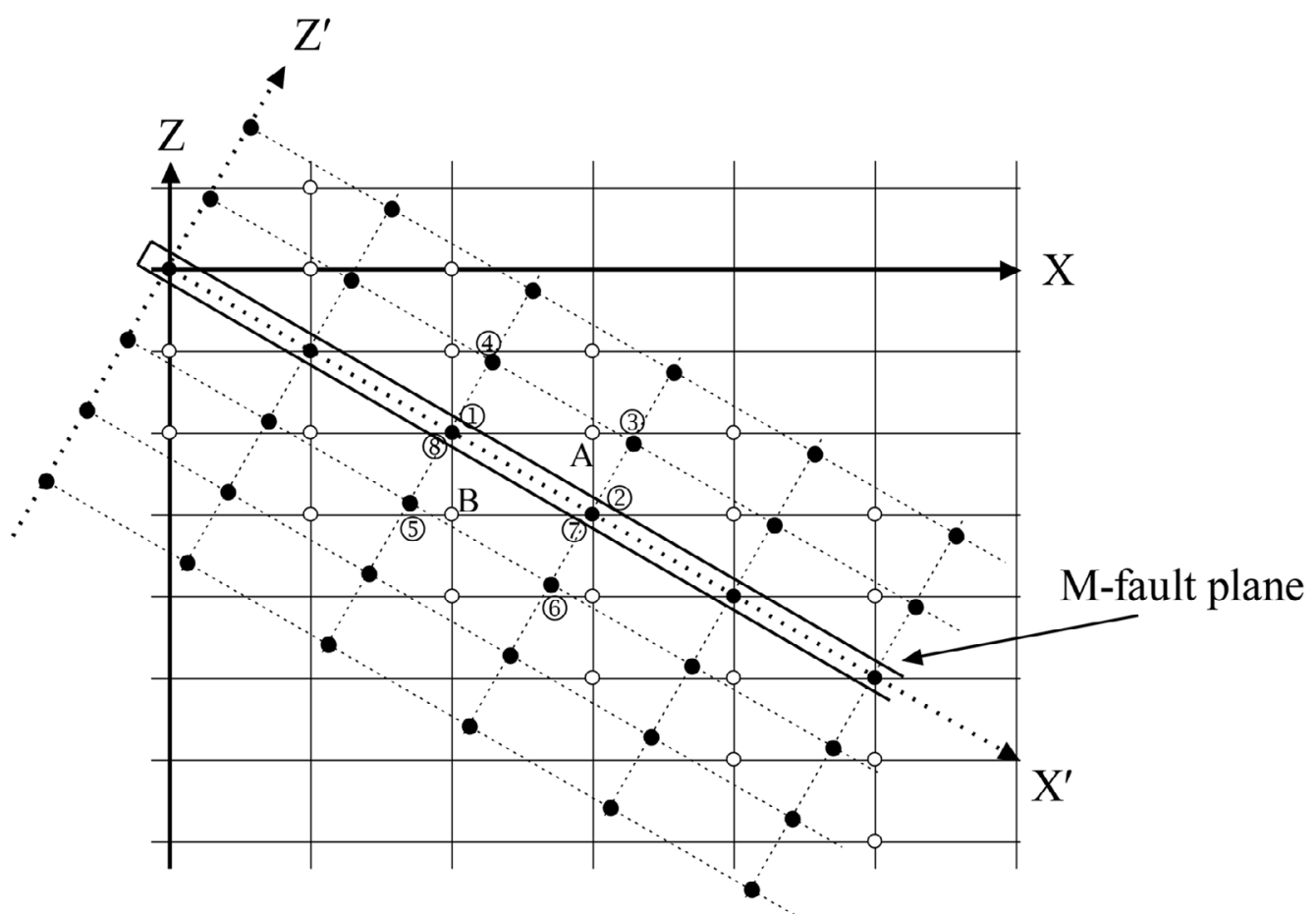

Fig. 2. Vertical profile of grid points for the F-coordinate (in black) and O-coordinate (in white). The values at the white grids just above (marked by A) and below (marked by B) the M-fault plane are computed through 2-D interpolation from those at the black grids: A (in the O-coordinate) from (1), (2), (3), and (4) (in the F-coordinate) and B (in the O-coordinate) from (5), (6), (7), and (8) (in the F-coordinate). 


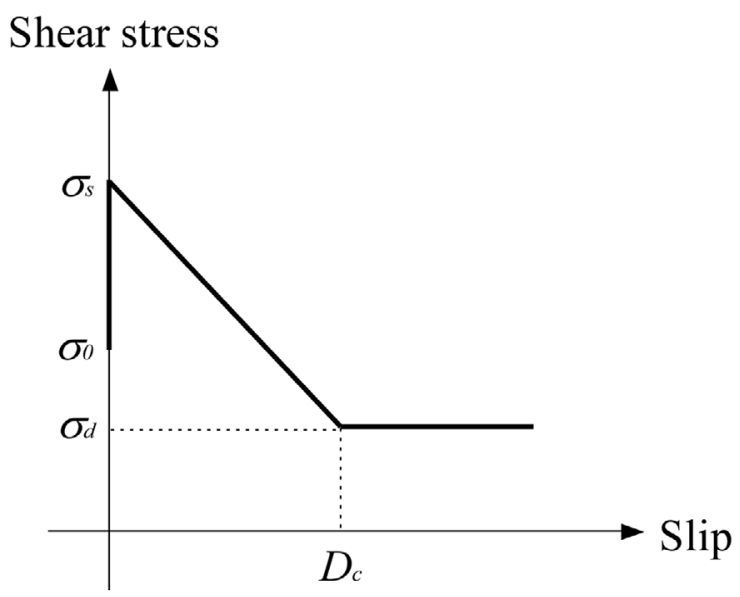

Fig. 3. The slip-weakening fracture criteria for shear stress, $\sigma, \sigma_{0}$ is the initial shear stress; $\sigma_{s}$ is the maximum static frictional stress; $\sigma_{d}$ is the dynamic frictional stress; and $D_{c}$ is the critical displacement. When $\sigma>\sigma_{s}$, the slip starts. When the slip is less than $D_{c}, \sigma$ decreases linearly with increasing slip. When the slip reaches $D_{c}, \sigma=\sigma_{d}$.

where $u$ is displacement, $\rho$ is density, and $\lambda$ and $\mu$ are Lamé constants. Except at the location of the initial rupture on the fault plane; the displacements and velocities are all zero:

$u_{x}=u_{y}=u_{z}=0\left(u_{x^{\prime}}=u_{y^{\prime}}=u_{z^{\prime}}=0\right)$

$\dot{u}_{x}=\dot{u}_{y}=\dot{u}_{z}=0\left(\dot{u}_{x^{\prime}}=\dot{u}_{y^{\prime}}=\dot{u}_{z^{\prime}}=0\right)$

The initial external stresses are represented by:

$\sigma=\left(\begin{array}{ccc}\sigma_{X X} & 0 & 0 \\ 0 & \sigma_{Y Y} & 0 \\ 0 & 0 & \sigma_{Z Z}\end{array}\right)$

Where $\sigma_{X X}$ and $\sigma_{Y Y}$ are the stresses along the directions of two horizontal compressive stresses which are in an inward direction as shown in Fig. $1 \mathrm{~b}$ and $\sigma_{\mathrm{ZZ}}$ is in the vertical direction.

To calculate the stresses on the M-fault, the initial stresses must be rotated from the O-coordinate onto the Fcoordinate using the following two steps. First, the initial regional stresses are rotated $\phi$ degrees counter-clockwise to the Z-axis (Fig. 1b). Thus,

$\sigma^{\prime}=A_{z}(\phi) \sigma A_{z}^{T}(\phi)$

Where $A_{z}(\phi)$ is the rotational matrix with a symmetric axis in the vertical direction. Second, the initial regional stresses are rotated $\delta$ degrees counter-clockwise to the Y-axis. Thus,

$\sigma^{\prime \prime}=A_{y}(\delta) \sigma^{\prime} A_{y}^{T}(\delta)$ where $A_{y}(\delta)$ is the rotational matrix with a symmetric axis in the direction of the strike. The normal stress on the Mfault is now:

$\sigma_{n o r}^{M}=\sigma_{z z}^{\prime \prime}$

and the shear stress is:

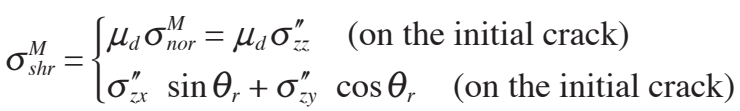

where $\mu_{d}$ is the dynamic frictional coefficient. For the noninitial crack grids, the direction, $\theta_{r}$ of the rupture is identified from the shear stress from $\sigma_{z x}^{\prime \prime}$ and $\sigma_{z y}^{\prime \prime}$ in Eq. (7b) and $\theta_{r}=\tan ^{-1}\left(\sigma_{z x}^{\prime \prime} / \sigma_{z y}^{\prime \prime}\right)$.

Similarly, for the N- and S-faults the applied regional stresses are rotated by $\phi$ degrees counter-clockwise onto the O-coordinate, as shown in Eq. (6). For these two sub-faults, the normal stress is:

$\sigma_{n o r}^{N}=\sigma_{y y}^{\prime}$

and the shear stress is:

$\sigma_{s h r}^{N}=\sigma_{y x}^{\prime}\left(\right.$ due to $\left.\sigma_{y z}^{\prime}=0\right)$

The boundary conditions for the M-fault in the F-coordinate are:

$u_{x^{\prime}}=$ continuous

$u_{y^{\prime}}=$ continuous

$u_{z^{\prime}}=$ continuous

and

$\sigma_{z^{\prime} x^{\prime}}=\sigma_{z x}^{\prime \prime}+\mu \frac{\partial u_{z^{\prime}}}{\partial x^{\prime}}+\mu \frac{\partial u_{x^{\prime}}}{\partial z^{\prime}}=$ continuous

$\sigma_{z^{\prime} y^{\prime}}=\sigma_{z y}^{\prime \prime}+\mu \frac{\partial u_{z^{\prime}}}{\partial y^{\prime}}+\mu \frac{\partial u_{y^{\prime}}}{\partial z^{\prime}}=$ continuous

$\sigma_{z^{\prime} z^{\prime}}=\sigma_{z z}^{\prime \prime}+\lambda \frac{\partial u_{x^{\prime}}}{\partial x^{\prime}}+\lambda \frac{\partial u_{y^{\prime}}}{\partial y^{\prime}}$

$+(\lambda+2 \mu) \frac{\partial u_{z^{\prime}}}{\partial z^{\prime}}=$ continuous

When the fault breaks, the boundary conditions are Eqs. (9c) and (10c), and the shear stress obeys slip-weakening fracture criteria (see Fig. 3); thus, 


$$
\begin{aligned}
\sigma_{s h r}^{M} & =\left\{\begin{array}{l}
\mu_{s} \sigma_{z^{\prime} z^{\prime}}-\frac{\mu_{s} \sigma_{z^{\prime} z^{\prime}}-\mu_{d} \sigma_{z^{\prime} z^{\prime}}}{D_{c}} \Delta u_{r^{\prime}} \quad\left(\Delta u_{r^{\prime}}<D_{c}\right) \\
\mu_{d} \sigma_{z^{\prime} z^{\prime}} \quad\left(\Delta u_{r^{\prime}} \geq D_{c}\right)
\end{array}\right. \\
& =\text { continuous }
\end{aligned}
$$

where $\Delta u_{r^{\prime}}=\sqrt{\left(u_{x^{\prime}}^{+}-u_{x^{\prime}}^{-}\right)^{2}+\left(u_{y^{-}}^{+}-u_{y^{\prime}}^{-}\right)^{2}} / 2$ is the slip in the direction of the rupture; $u_{i}^{+}$and $u_{i}^{-}$are the displacements on the hanging wall and the footwall of the fault, respectively; $\mu_{s}$ is the static frictional coefficient. The boundary conditions for the $\mathrm{N}$ - and $\mathrm{S}$-faults in the original coordinates are:

$u_{x}=$ continuous

$u_{y}=$ continuous

$u_{z}=$ continuous

likewise the stresses are continuous:

$\sigma_{y x}=\sigma_{y x}^{\prime}+\mu \frac{\partial u_{y}}{\partial x}+\mu \frac{\partial u_{x}}{\partial y}=$ continuous

$\sigma_{y y}=\sigma_{y y}^{\prime}+\lambda \frac{\partial u_{x}}{\partial x}+(\lambda+2 \mu) \frac{\partial u_{y}}{\partial y}+\lambda \frac{\partial u_{z}}{\partial z}$

$=$ continuous

$\sigma_{y z}=\sigma_{y z}^{\prime}+\mu \frac{\partial u_{y}}{\partial z}+\mu \frac{\partial u_{z}}{\partial y}=$ continuous

Similarly, when a fault rupture occurs, the boundary conditions are Eqs. (12b) and (13b); the shear stress obeys the slip-weakening fracture criteria. Thus, we have:

$$
\begin{aligned}
\sigma_{s h r}^{N}=\sigma_{s h r}^{S} & = \begin{cases}\mu_{s} \sigma_{y y}-\frac{\mu_{s} \sigma_{y y}-\mu_{d} \sigma_{y y}}{D_{c}} \Delta u_{r} & \left(\Delta u_{r}<D_{c}\right) \\
\mu_{d} \sigma_{y y}\end{cases} \\
& =\text { continuous }
\end{aligned}
$$

where $\Delta u_{r}=\sqrt{\left(u_{x}^{+}-u_{x}^{-}\right)^{2}+\left(u_{y}^{+}-u_{y}^{-}\right)^{2}} / 2$.

As mentioned above, the fault edges are located $4 \mathrm{~km}$ below the free surface. Nevertheless, the free surface boundary condition proposed by Ilan and Loewenthal (1976) is used. The absorption boundary method is used for 3-D finite differences (Higdon 1991). The wave equations are replaced by central finite difference equations. The boundary conditions on the fault are derived following the procedures suggested by Horikawa (1996) (see the Appendix for an example of the calculations of $\sigma_{z^{\prime} z^{\prime}}$ and $u_{x^{\prime}}$ on the M-fault). A detailed description of the derivation of stresses and slip can be found in Wang (2005).
The rupture starts from the M-fault center (marked with a star in Fig. 1a) where the finite difference is performed on the F-coordinate (i.e., the $\mathrm{X}^{\prime}, \mathrm{Y}^{\prime}$, and $\mathrm{Z}^{\prime}$ axes) per the black circles connected with the dashed lines in the vertical profile of Fig. 2. The grid points on the O-coordinate are denoted by white circles, and the difference values on the white circles are retrieved from those at the black grid points in two hanging blocs and two foot blocs of the M-fault by means of a 2-D interpolation (Press et al. 1992). For example, the values at black grid points (1), (2), (3), and (4) (in the F-coordinate system) in the hanging bloc are used to interpolate the values at white grid point $\mathrm{A}$ (in the O-coordinate system). Similarly, the value at grid point $B$ in the foot bloc is interpolated from those at (5), (6), (7), and (8). Note that the values at two pairs of grid points, i.e., (1) and (8) as well as (2) and (7), on the $\mathrm{M}$-fault plane are the same before the rupture, yet become different afterwards because of the slip discontinuity on the ruptured plane. A similar interpolation is performed for all of the white grid points that are right above and right below the fault plane. At this step, the slips at the grid points are in the F-coordinate system and must be rotated into the O-coordinate system; they must be rotated onto the O-coordinate for the computations of the 3-D finite differences in these coordinates for the remaining grid points.

\section{PARAMETERS AND STABILITY CONDITIONS}

The values and orientations of initial external stresses given in Table 1 were taken from Kase and Kuge (1998, 2001) and were tested through numerical simulations by Wang (2005). The stresses can trigger the strike-slip subfaults due to the break of the thrust main fault. From Coulomb's friction law (Harris and Day 1993), the shear stress and the maximum static frictional stress in spatial and temporal distribution are described by the following equation:

$$
\Delta s(t)=\mu_{s}\left|\sigma_{n o r}^{0}+\sigma_{n o r}(t)\right|-\left|\sigma_{s h r}^{0}+\sigma_{s h r}(t)\right|
$$

where $\sigma_{\text {nor }}^{0}$ is the initial normal stress on the sub-fault; $\sigma_{\text {nor }}(t)$ is the change of normal stress on the sub-fault at time $t$; $\sigma_{s h r}^{0}$ is the initial shear stress on the sub-fault; and $\sigma_{s h r}(t)$ is the change of shear stress on the sub-fault at time $t$.

When $\Delta s(t)$ is negative, the segment can be triggered to rupture. From the initial external stresses given in Table 1, the relation between $\phi$ and $\Delta s$ on the two strikeslip sub-fault planes at $t=0 \mathrm{~s}$ is shown in Fig. 4. Obviously, the minimum of $\Delta s$ is at $\phi=30^{\circ}$, thus indicating that the sub-faults can be most easily triggered at $\phi=30^{\circ}$. Therefore, the simulations and numerical tests of parameters in use are made only at $\phi \pm 1^{\circ}$ for each $\phi$.

From the tests, we find that the two strike-slip subfaults (i.e., the $\mathrm{N}$ - and $\mathrm{S}$-faults) can be triggered to rupture 
only when $18^{\circ}<\phi<42^{\circ}$ and the range of $\phi$ depends on the fault system. The initial stresses on the fault system are $\sigma_{X X}$ , $\sigma_{Y Y}$ and $\sigma_{Z Z}$. We must transfer them from the tectonic system to the fault plane. This gives the angle $\tan ^{-1}\left(\sigma_{z x}^{\prime \prime} / \sigma_{z y}^{\prime \prime}\right)$, which is the maximum shear stress direction. According to the tectonics, the maximum stress direction will be a raked direction of the fractured fault. In this study, the rake angle of the main fault is set to be $60^{\circ}$, so that the $\phi$ angle is $26.57^{\circ}$. The sampling time interval, $d t$, is required to meet the computational stability of the finite differences (Kelly et al. 1976), i.e.,

$d t \leq d s / \sqrt{\alpha^{2}+\beta^{2}}$

where $d s$ is the grid size; and $\alpha$ and $\beta$ are, respectively, the $\mathrm{P}$ - and S-wave velocities. Thus, for $d s \geq 0.05 \mathrm{~km} d t=0.01 \mathrm{~s}$ can meet the stability condition of Eq. (16).
Although the rupture velocity cannot be determined from this model, several authors (e.g., Andrews 1976; Das and Aki 1977; Day 1982; Harris and Day 1993) stated that the rupture velocity can be identified from the difference between the maximum static frictional stress $\left(\sigma_{s}\right)$ and the initial stress $\left(\sigma_{0}\right)$ as well as from the difference between dynamic frictional stress $\left(\sigma_{d}\right)$ and initial stress $\left(\sigma_{0}\right)$. Andrews (1976) and Das and Aki (1977) defined the parameter $S$ by the four stresses to represent the differences on rupture velocities, i.e.,

$S=\left(\sigma_{s}-\sigma_{0}\right) /\left(\sigma_{0}-\sigma_{d}\right)$

When $S \geq 1.63$, the rupture velocity is less than the Rayleighwave velocity, and it increases with rupture length and eventually approaches the latter. By contrast, when $S<1.63$, the rupture velocity starts from the sub-Rayleigh velocity and

Table 1. The parameters and their values used in numerical simulations.

\begin{tabular}{|c|c|}
\hline Maximum compressional stress: $\sigma_{X X}(\mathrm{MPa})$ & 58.0 \\
\hline Minimum compressional stress: $\sigma_{Y Y}$ and $\sigma_{Z Z}(\mathrm{MPa})$ & 20.0 \\
\hline Initial shear stress: $\sigma_{0}(\mathrm{MPa})$ & 15.2 \\
\hline Dynamic frictional stress: $\sigma_{d}(\mathrm{MPa})$ & 5.52 \\
\hline Maximum static frictional stress: $\sigma_{s}(\mathrm{MPa})$ & 16.56 \\
\hline P-wave velocity: $\alpha\left(\mathrm{km} \mathrm{s}^{-1}\right)$ & 4.6 \\
\hline S-wave velocity: $\beta\left(\mathrm{km} \mathrm{s}^{-1}\right)$ & 2.66 \\
\hline Density: $\rho\left(\mathrm{g} \mathrm{cm}^{-3}\right)$ & 2.5 \\
\hline Critical displacement: $D_{c}(\mathrm{~m})$ & 0.1 \\
\hline Static coefficient of friction: $\mu_{s}$ & 0.6 \\
\hline Dynamic coefficient of friction: $\mu_{d}$ & 0.2 \\
\hline Grid length in time: $d t(\mathrm{~s})$ & 0.01 \\
\hline \multicolumn{2}{|l|}{ M-fault } \\
\hline Length: $\mathrm{L}_{\mathrm{M}}(\mathrm{km})$ & 8.0 \\
\hline Width: $\mathrm{W}_{\mathrm{M}}(\mathrm{km})$ & 4.0 \\
\hline Strike, Dip, Rake & $0^{\circ}, 30^{\circ}, 60^{\circ}$ \\
\hline \multicolumn{2}{|l|}{ N-fault } \\
\hline Length: $\mathrm{L}_{\mathrm{N}}(\mathrm{km})$ & 3.46 \\
\hline Width: $\mathrm{W}_{\mathrm{N}}(\mathrm{km})$ & 2.0 \\
\hline Strike, Dip & $90^{\circ}, 90^{\circ}$ \\
\hline \multicolumn{2}{|l|}{ S-fault } \\
\hline Length: $\mathrm{L}_{\mathrm{S}}(\mathrm{km})$ & 3.46 \\
\hline Width: $\mathrm{W}_{\mathrm{s}}(\mathrm{km})$ & 2.0 \\
\hline Strike, Dip & $90^{\circ}, 90^{\circ}$ \\
\hline
\end{tabular}




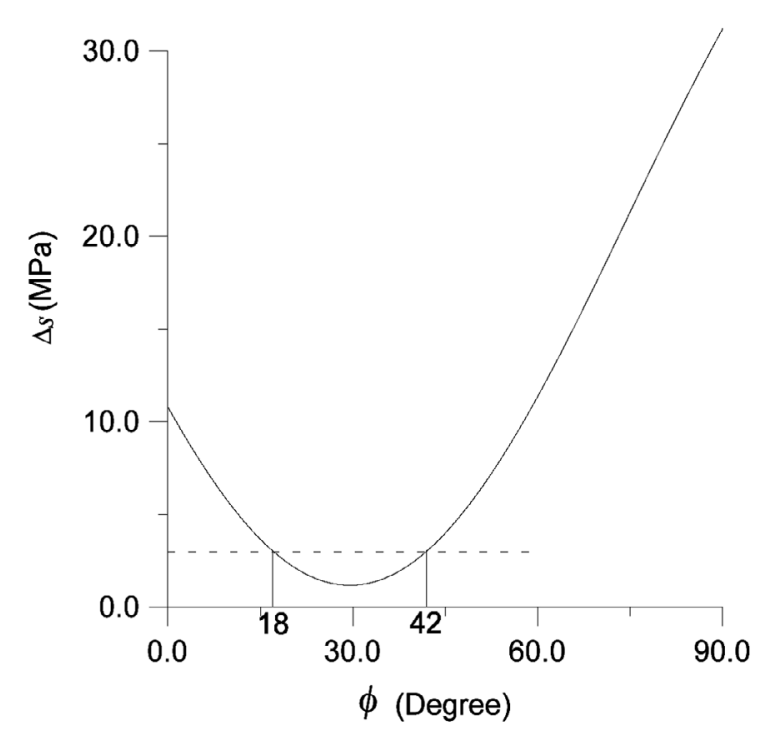

Fig. 4. The relation between $\phi$ and $\Delta s$ on the two strike-slip sub-fault planes at $t=0 \mathrm{~s}$.

increases with rupture length and can in fact be greater than the S-wave velocity or even approach the P-wave velocity (Aki and Richards 1980; Wang 1996, 2012). The sub-Rayleigh velocity is the velocity of rupture waves which is slower than the velocity of Rayleigh waves. In this study, for the ruptures on the thrust fault and the triggering on two sub-faults, the set of the initial external stresses is shown in Table 1. Obviously, the value of $S$ is smaller than 1.63 on the M-fault, and thus the rupture velocity can approach the P-wave velocity.

\section{SIMULATION RESULTS}

Using the parameters listed in Table 1 along with $\phi=$ $26.57^{\circ}$ (or $\theta=63.43^{\circ}$ ), which gives a rake of $60^{\circ}$ in the finite difference computations, and the initial rupture occurs at the center of the M-fault (designated as a star in Fig. 1). The equal-time contours of ruptures on the three faults are illustrated in Fig. 5, in which the view is set to be in the direction perpendicular to the fault plane and from the hanging wall. In Fig. 5, the numbers represent the times of ruptures in seconds. When $t=0 \sim 1 \mathrm{~s}$ (Figs. $5 \mathrm{a}-\mathrm{c}$ ), the M-fault starts to rupture from its center (Fig. 5a) and when the rake is $60^{\circ}$, the rupture velocity is faster along the dip than along the strike. In this time period, the ruptures propagate outward, while the S- and $\mathrm{N}$-faults are still locked. Overall, it takes about $1.71 \mathrm{~s}$ to make the $\mathrm{M}$-fault completely rupture. Figure $5 \mathrm{~d}$ shows that the $\mathrm{S}$ - and $\mathrm{N}$-faults start to rupture at $t \sim 1.37 \mathrm{~s}$. The S-fault (see the left panel) and $\mathrm{N}$-fault (see the right panel) are both triggered at a depth of $5 \mathrm{~km}$, but the ruptures on the two sub-faults propagate along the opposite directions. The two sub-faults continue to rupture for about $2.23 \mathrm{~s}$ (Fig. 5f). It is noted that the asymmetric rupture patterns on the $\mathrm{S}$ - and $\mathrm{N}$-faults are caused by different ruptures from the M-fault: downward and upward ruptures on the $\mathrm{S}$ - and $\mathrm{N}$-faults, respectively.

From the values of model parameters given in Table 1, the calculated value of $S$ is 0.14 and less than 1.63. The rupture velocity increases with rupture length and can be higher than the S-wave velocity or even approach the P-wave velocity. From Fig. 5b, the break tip is $1.8 \mathrm{~km}$ and time is $0.5 \mathrm{~s}$, so the rupture velocity is $3.6 \mathrm{~km} \mathrm{~s}^{-1}$, which is higher than the $\mathrm{S}$-wave velocity. From Fig. $5 \mathrm{c}$, the break tip is $3.7 \mathrm{~km}$, so the rupture velocity is $3.7 \mathrm{~km} \mathrm{~s}^{-1}$. Results suggest an increase in the rupture velocity with the rupture length.

The time-dependent displacements for the three faults are shown in Figs. 6a - $\mathrm{f}$. The maximum slip on the M-fault occurs at the center of the initial crack (Fig. 6a) and increases with time. From Figs. 6e and f, we can see that when the displacement of M-fault does not change significantly, the fault is almost stable and thus the slip ceases. The two sub-faults start to rupture about at $t=1.37 \mathrm{~s}$. However, their displacements are not zero before they break because the waves generated from the M-fault passed through the two sub-faults. This can be seen from the panels on the left and right in Fig. 6c. The displacements on the two sub-faults are basically the same, but the patterns are asymmetric. Small differences are observed at $t=2.5 \mathrm{~s}$. The differences are attributed to different amounts of later reflections from the free surface at different depths. The variations in the timedependent shear stresses on the three faults are shown in Figs. $7 \mathrm{a}-\mathrm{f}$. Since the variations in normal stresses are very small, they are not displayed in Fig. 7. At $t=0$, on the Mfault, the stress drops occur only at the site where the initial crack occurs and does not change at others. At $t=0.5 \sim 1.5 \mathrm{~s}$, the maximum shear stress appears at the boundaries between the cracked and un-cracked regions, as displayed by blue in Figs. $7 b-d$. These are crack tips which are ready to induce further cracks. At $t=2$ and $2.5 \mathrm{~s}$, the displacements within the M-fault are greater than the critical displacement $\left(D_{c}\right)$ (see Fig. 3). In other words, when the slip distance is equal to $D_{c}$, the shear stress is equal to the dynamic frictional strength, and thus, does not decrease further (Figs. 7e and f). At $t=0 \sim 1 \mathrm{~s}$, the shear stresses on the $\mathrm{S}$ - and $\mathrm{N}$-faults change very little (see the left- and right-hand panels of Figs. 7a - c). At $t=1.5 \mathrm{~s}$ (Fig. 7d), significant increases in the shear stresses caused by the ruptures on the M-fault are observed in the left- and right-hand panels of Fig. $7 \mathrm{~d}$ and trigger the failure of the two sub-faults. At $t=2$ to $2.5 \mathrm{~s}$, the ruptures occur on the two sub-faults with a similar propagation pattern as happened on the M-fault.

\section{DISCUSSION}

To study fault interaction, it is very important to locate the minimum distance from which the main fault is capable of triggering sub-faults. This distance may depend on the mainshock magnitude, the geometry of the main fault and 
(a)

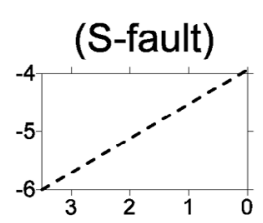

(b)

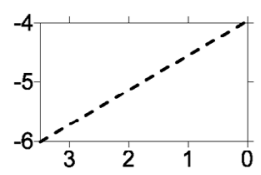

(c)

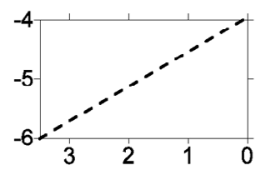

(d)

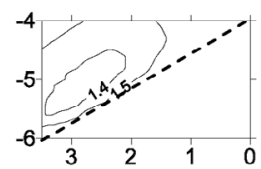

(e)

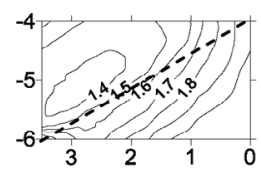

(f)

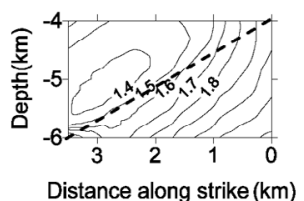

$0 \sec ($ M-fault)

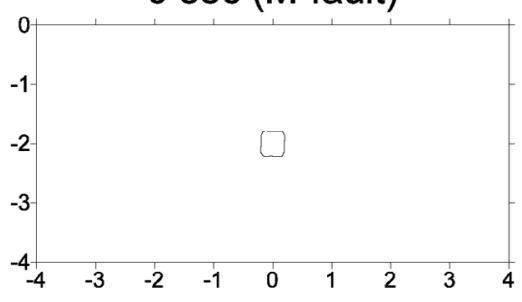

$0.5 \mathrm{sec}$

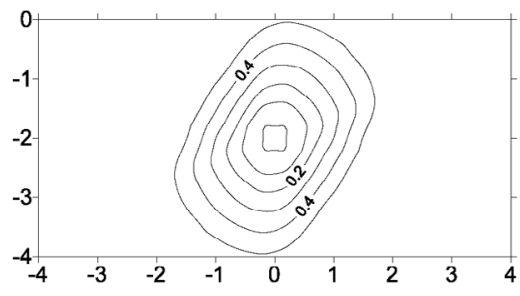

$1 \mathrm{sec}$

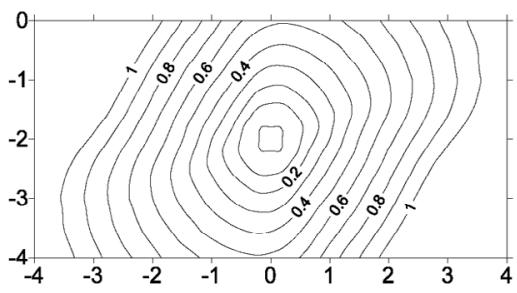

$1.5 \mathrm{sec}$

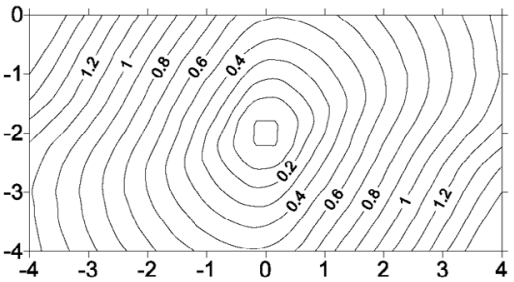

$2 \mathrm{sec}$

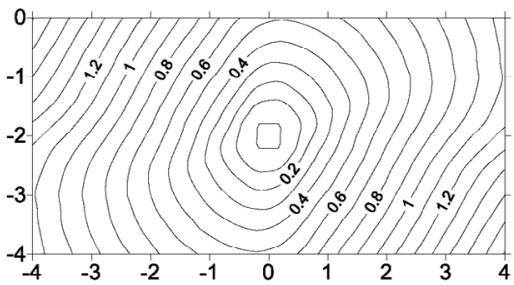

$2.5 \mathrm{sec}$

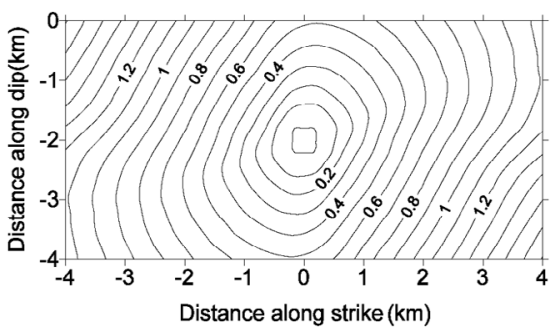

(N-fault)
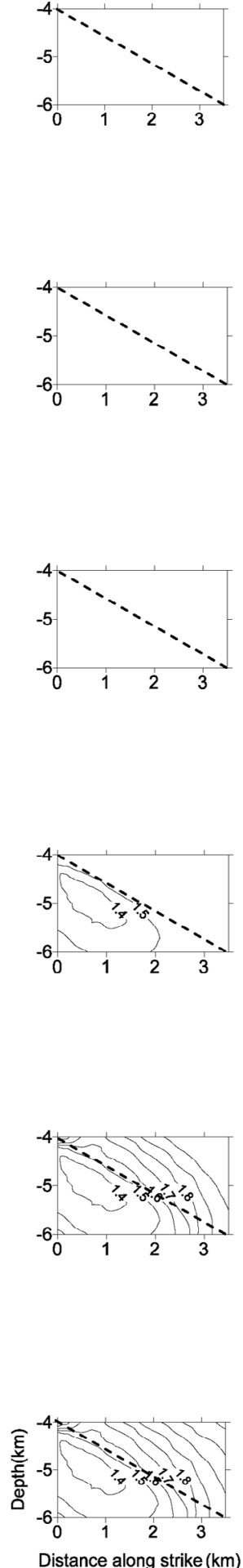

Fig. 5. Rupture propagation on the main thrust (central) from 0 to $2.5 \mathrm{~s}$ (a to f) and triggering of ruptures in two sub strike-slip faults (panel on the right-hand side for the S-fault and that on the left-hand side for the $\mathrm{N}$-fault). It takes about $1.71 \mathrm{~s}$ for ruptures to extend from the initiation point to the entire M-fault. The two sub-faults are triggered at the time of about $1.37 \mathrm{~s}$. The dashed line plotted on the two sub strike-slip faults are the projection of the intersection with the M-fault. 

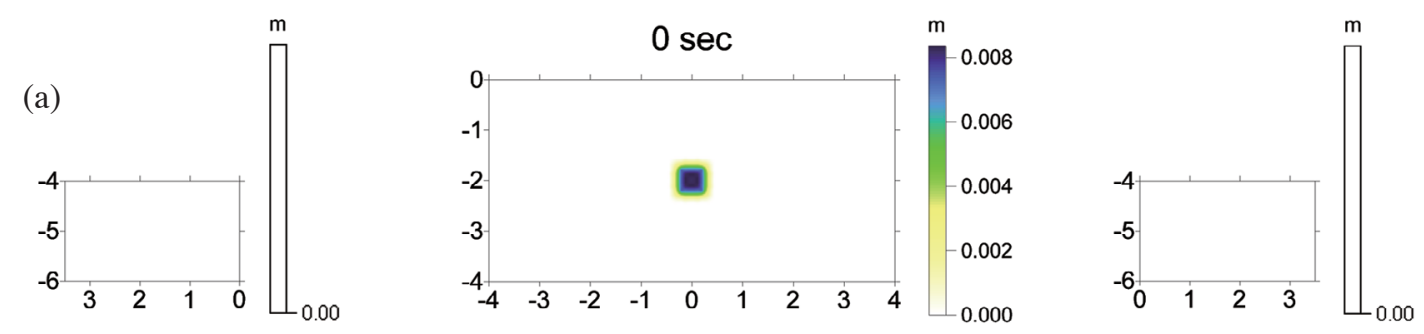

(b)
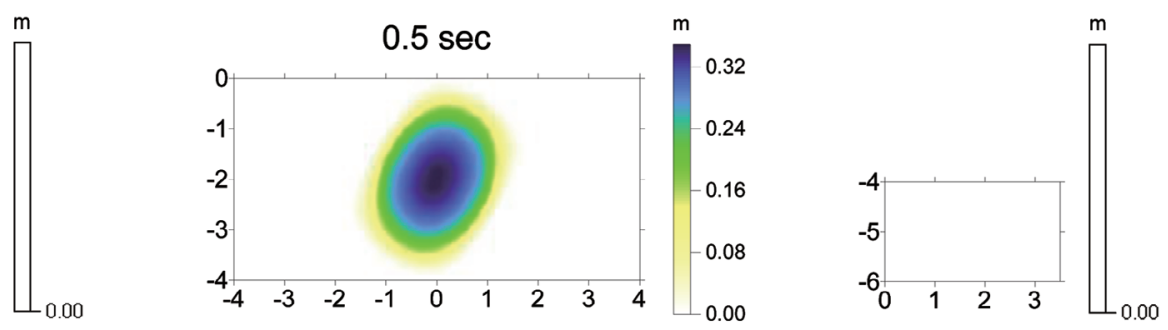

(c)
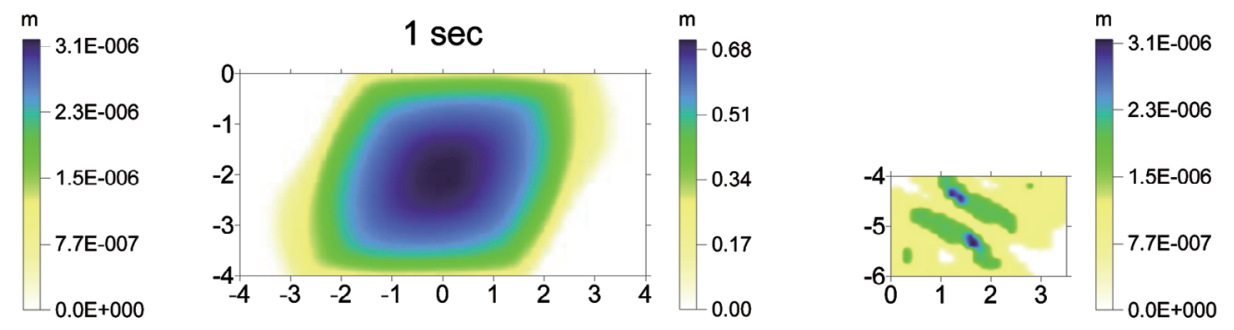

(d)
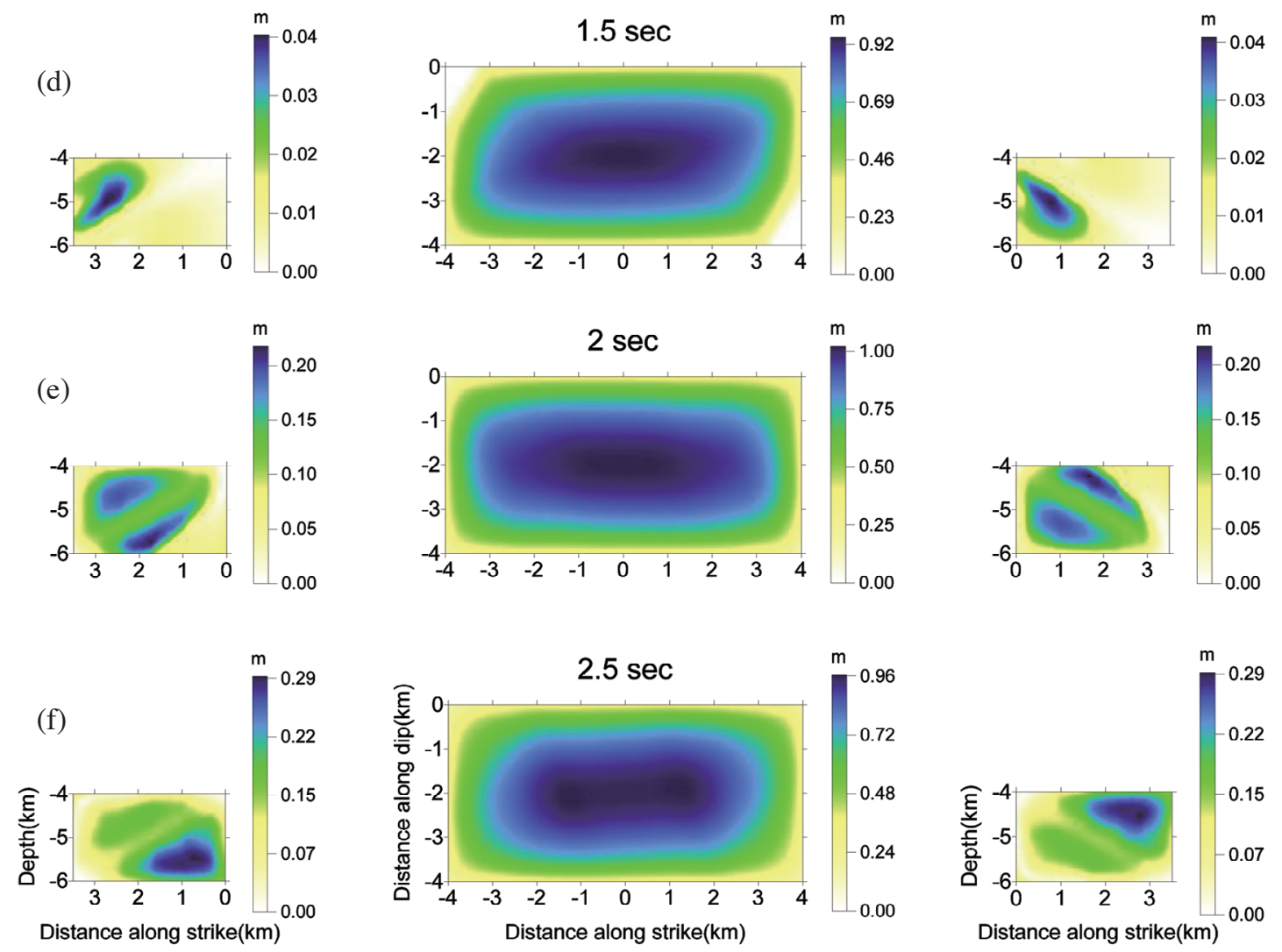

Fig. 6. Figure shows the time-dependent displacements of the three faults. There is the same description as mentioned in Fig. 5. The slip starts at the center of the $\mathrm{M}$-fault (a) and reaches a steady value after the rupture is completed. The asymmetric displacement patterns are caused by upward (N-fault) and downward (S-fault) rupture propagations. 

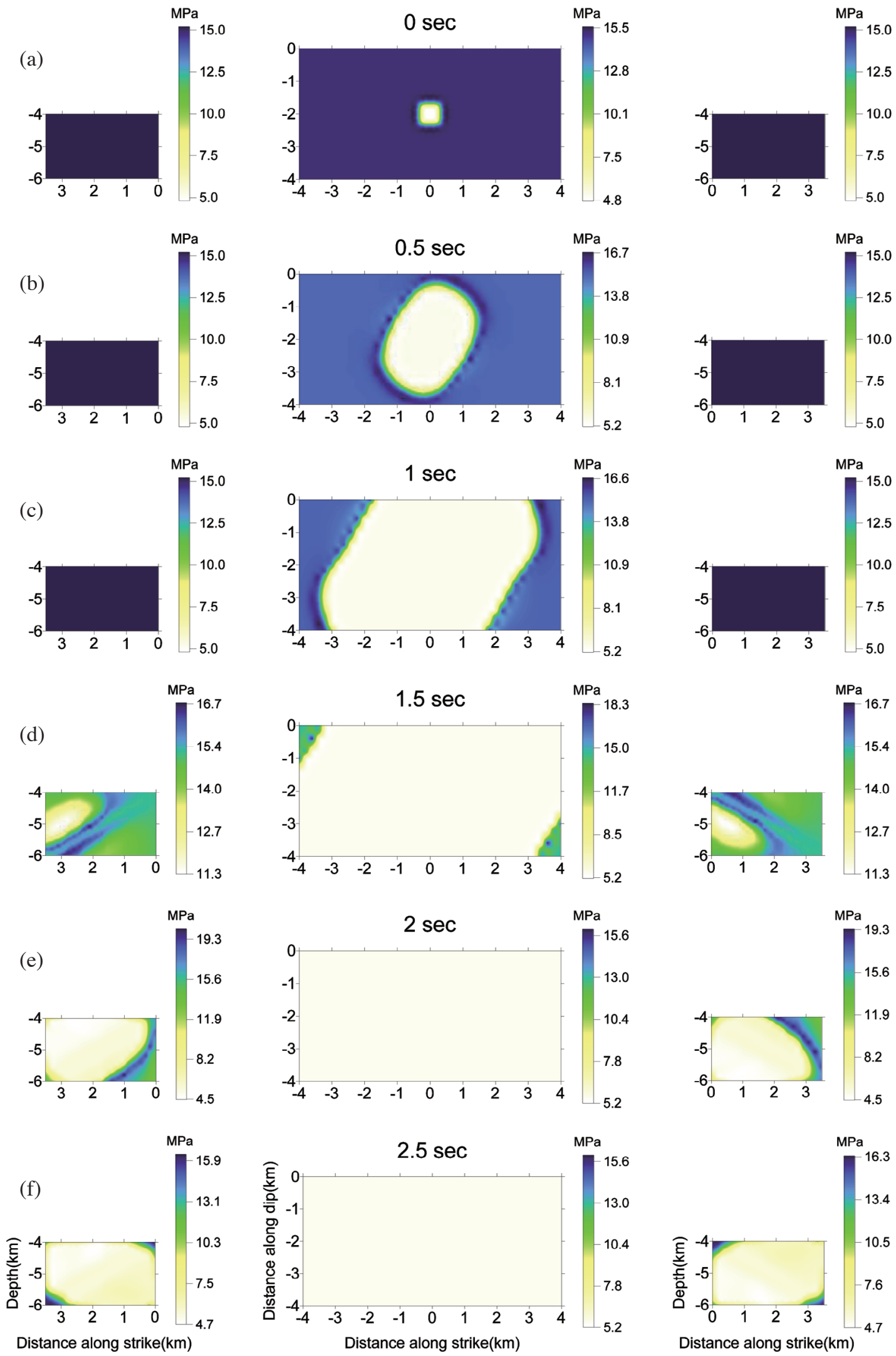

Fig. 7. Figure shows the time-dependent displacements of the three faults. There is the same description as mentioned in Fig. 5 . At $t=0$, stress drop is only observed at the site where the initial crack occurs, while all other regions maintain regional stress. The stress drop extends outward with time, as shown in a to $\mathrm{f}$. The maximum shear stress appears at the boundaries of the cracked and un-cracked regions, as indicated by the blue shading in $\mathrm{b}$ to $\mathrm{d}$; these represent crack tips and are ready to induce further cracks. A similar phenomenon is observed for the $\mathrm{N}$-fault (right side) and $\mathrm{S}$-fault (left side). 
sub-faults. Here, we will change the positions of the two sub-faults, as shown in Fig. 8, to investigate the possible effects of the spatial structure of the fault system triggering the two sub-faults. The northern and southern ends in each panel of Fig. 8 marked by two slashed rectangles represent the triggered ruptured source regions (denoted by TRSR) where there are larger stress changes. The TRSR can be clearly identified based on the M-fault model. Based upon rupture-time contours and the initial triggered rupture area in Fig. 5f, we believe that if the sub-fault can completely rupture, most of the sub-fault must be within the area where the ruptures of the main fault stopped first. It is found that such an area is in between 0 and $1.73 \mathrm{~km}$ (measured from the western edge of the M-fault) on the $\mathrm{N}$-fault and in between 1.73 and $3.46 \mathrm{~km}$ on the S-fault. But, the TRSR would be distinct for different models and model parameters. This means that when a sub-fault or any part of the two sub-faults in a to-be-triggered region, it could be triggered and would completely rupture. When the two sub-faults in Fig. 8a are shifted somewhat to the western portion of the M-fault, their eastern edges are still on the western edge of the Mfault. Hence, the two sub-faults are, respectively, inside and outside of the to-be-triggered regions. For this case, the Nfault ruptures completely, and the equal-time contours of ruptures become narrower at the place near $-1 \mathrm{~km}$ (in the $\mathrm{X}$-direction). However, it is not easy to interpret this phenomenon due to a complicated pattern of stress propagation. On the S-fault, only a local portion breaks and ruptures do not propagate over the entire fault plane. The incomplete rupture on the S-fault is due to low stresses exerted on it caused by the rupture on the M-fault.

In order to shift the two sub-faults from the M-fault as mentioned above, we define the distance of $0.865 \mathrm{~km}$ to be a length unit. First of all, the two sub-faults are shifted $3.46 \mathrm{~km}$ (or 4 length units), their respective eastern edges are on the western edge of the M-fault, move the two subfaults eastward by step in 1 unit length and calculating the triggering rupture until their respective western edges are on the eastern edge of the M-fault, as shown in Figs. $8 \mathrm{a}$ - i. Figures. $8 \mathrm{a}-\mathrm{g}$ show that the $\mathrm{N}$-fault is located in the north part of TRSR, and can be triggered with a complete rupture. But, in Figs. 8h and i, the N-fault is outside the TRSR, it will be triggered with an incomplete rupture. On the other hand, when the S-fault is located in the south part of TRSR, it can be triggered with a complete rupture, as shown in Figs. 8c - i. When the S-fault is outside the TRSR, it will be triggered with an incomplete rupture, as shown in Figs. 8a and b.

Obviously, simulations are carried to explore the triggering effects resulting from the related positions, along the east-west direction, which are perpendicular to the strike direction of the M-fault to the sub-faults. Meanwhile, the simulations were also conducted to study the effects due to the change of the distances between the M-fault and the subfaults along the north-south direction which is parallel to the strike. Results are shown in Fig. 9. In Figs. 9a - e (i.e., the left and right panels for the $\mathrm{S}$ - and $\mathrm{N}$-faults, respectively) we can see the modes of complete, incomplete, and non-triggered ruptures for five different distances, i.e., 1.2, 1.6, 2.0, 2.4 , and $2.8 \mathrm{~km}$, away from the M-fault in the north-south direction. The rupture pattern of the M-fault is the same as before and is not shown here again. Simulation results clearly show that the two sub-faults can be triggered with complete ruptures only when the separation distances are shorter than $2.0 \mathrm{~km}$ (Figs. 9a - c) and with partial ruptures when the separation distances are in between 2.0 and $2.8 \mathrm{~km}$ (Fig. 9d). On the other hand, the sub-faults cannot be triggered when the separation distance is longer than $2.8 \mathrm{~km}$ (Fig. 9e). Of course, the separation distance in controlling triggering is not fixed at the value of $2.8 \mathrm{~km}$, and depends on the models with different directions and magnitudes of regional stresses. A key issue that cannot be ignored is the direction of the applied regional stress. According to our simulations, the two sub-faults of the model can be triggered only when the angle $\phi$ lies between $18^{\circ}-42^{\circ}$ as mentioned by Wang (2005). We found that the TRSR is no longer located on either the northern or southern side of the M-fault when $\phi<18^{\circ}$ or $\phi>42^{\circ}$. This means that the changes of shear stresses in the east-west component caused by the break of the M-fault are too small to trigger the two sub-faults.

\section{CONCLUSIONS}

In this study, we first develop and test a composite finite difference method to study the triggering and propagation of ruptures in a complex fault system with a main thrust and two strike-slip-type sub-faults which can be observed in central Taiwan. Two different grid sizes of the finite differences are performed for two different coordinates which are connected to each other by using a 2-D interpolation and coordinate transformation. This makes simultaneous computations for different faults geometrically possible thereby facilitating the study of fault interactions in such a complicated fault system.

The direction of applied regional stress does, of course, play a very important role in fault interactions, but this is, to a certain extent, limited. With a fixed direction of regional stress $\left(\phi=26.57^{\circ}\right.$ in this study), the present simulation results provide solid unambiguous evidence that the strike-slip-type sub-faults can be triggered and then rupture completely by the failure of a nearby thrust fault under two conditions. The first condition is that the strike-slip-type sub-fault must be located inside the range of a source region (TRSR) for to-be-triggered by the ruptures of the main thrust. The second condition is that the strike-slip-type subfault is not too far away from the main thrust. When the two conditions do not exist on the strike-slip-type sub-faults, the rupture-time contours are narrow or the sub-faults cannot completely rupture even though they are triggered. 


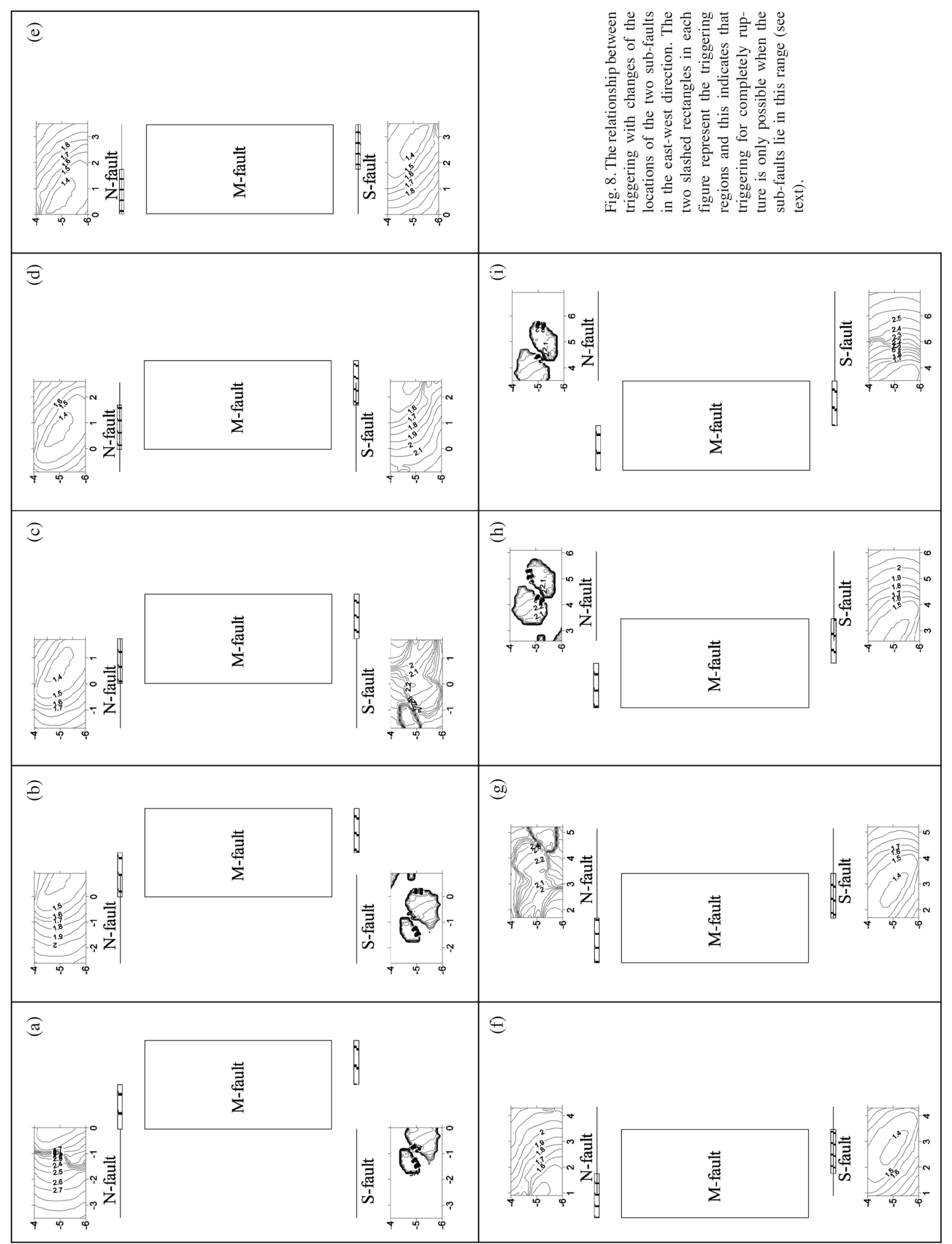


(S-fault)

(a)

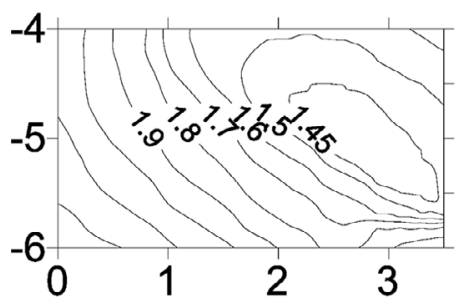

(b)

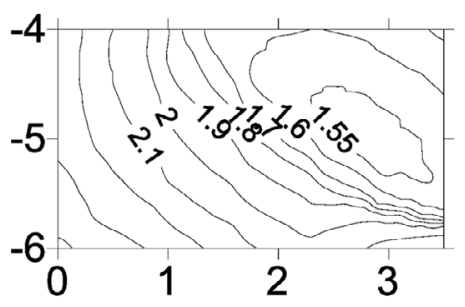

(c)

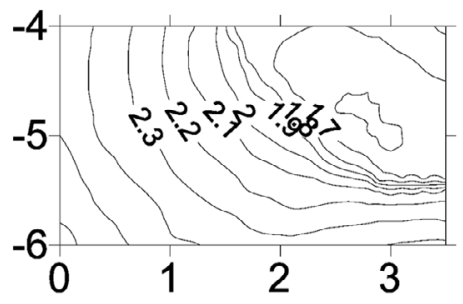

(d)

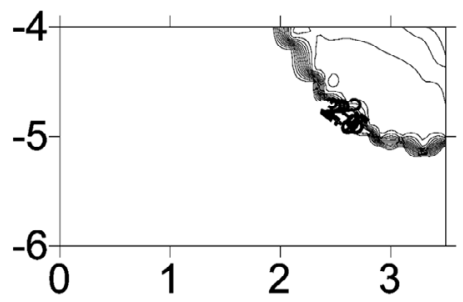

(e)

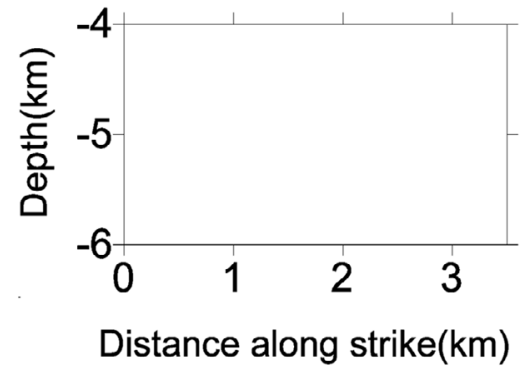

(N-fault)
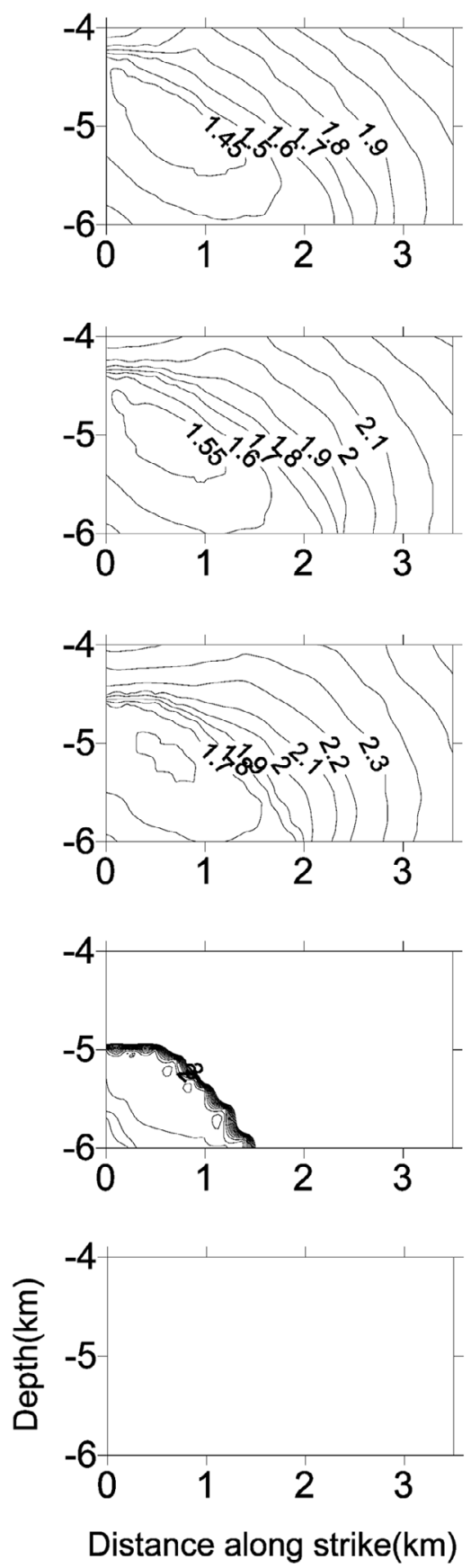

Fig. 9. The relationship between triggering with changes of the two sub-faults in the north-south direction. The distances between the M-fault and the sub-faults are: (a) for $1.2 \mathrm{~km}$; (b) for $1.6 \mathrm{~km}$; (c) for $2.0 \mathrm{~km}$; (d) for $2.4 \mathrm{~km}$; and (e) for $2.8 \mathrm{~km}$. The complete ruptures can be observed only for distances less than $2.0 \mathrm{~km}$.

In the present study, we simulate the rupture and triggering processes of a complex fault system composed by three faults. But, the real fault system is much more complicated than the present one. Hence, more studies will be conducted on the basis of numerical simulations to investigate the key factors, including the fault size, geometric patterns and ini- tial regional stresses, in influencing the triggering distance in the near future.

Acknowledgements The first author is grateful to Dr. Yuko Kase for providing the subroutine code for fault rupture modeling and for many discussions during the author's visit 
to the Japan Geological Survey. The authors thank two reviewers for giving significant suggestions and comments to substantially improve the article. This study was partly sponsored by Chia-Nan University of Pharmacy and Science.

\section{REFERENCES}

Aki, K., 1979: Characterization of barriers on an earthquake fault. J. Geophys. Res., 84, 6140-6148, doi: 10.1029/ JB084iB11p06140. [Link]

Aki, K. and P. G. Richards, 1980: Quantitative Seismology: Theory and Methods, W. H. Freeman, San Francisco.

Andrews, D. J., 1976: Rupture velocity of plane strain shear cracks. J. Geophys. Res., 81, 5679-5687, doi: 10.1029/ JB081i032p05679. [Link]

Chan, C. H. and R. S. Stein, 2009: Stress evolution following the 1999 Chi-Chi, Taiwan, earthquake: Consequences for afterslip, relaxation, aftershocks and departures from Omori decay. Geophys. J. Int., 177, 179-192, doi: 10.1111/j.1365-246X.2008.04069.x. [Link]

Das, S. and K. Aki, 1977: A numerical study of two-dimensional spontaneous rupture propagation. Geophys. $J$. R. Astr. Soc., 50, 643-668, doi: 10.1111/j.1365-246X. 1977.tb01339.x. [Link]

Day, S. M., 1982: Three-dimensional simulation of spontaneous rupture: The effect of nonuniform prestress. Bull. Seismol.Soc. Am., 72, 1881-1902.

Deffontaines, B., J.-C. Lee, J. Angelier, J. Carvalho, and J.-P. Rudant, 1994: New geomorphic data on the active Taiwan orogen: A multisource approach. J. Geophys. Res., 99, 20243-20266, doi: 10.1029/94JB00733. [Link]

Deffontaines, B., O. Lacombe, J. Angelier, H.T Chu, F. Mouthereau, C.T. Lee, J. Deramond, J.F. Lee, M.S. Yu, and P.M. Liew, 1997: Quaternary transfer faulting in the Taiwan Foothills: Evidence from a multisource approach. Tectonophysics, 274, 61-82, doi: 10.1016/ S0040-1951(96)00298-3. [Link]

Harris, R. A. and S. M. Day, 1993: Dynamics of fault interaction: Parallel strike-slip faults. J. Geophys. Res., 98, 4461-4472, doi: 10.1029/92JB02272. [Link]

Higdon, R. L., 1991: Absorbing boundary conditions for elastic waves. Geophysics, 56, 231-241, doi: 10.1190/ 1.1443035. [Link]

Horikawa, H., 1996: Inversion for dynamic source parameters: Application to the 1990 Izu-Oshima, Japan, earthquake. DSc Thesis, Kyoto University, Kyoto.

Ilan, A. and D. Loewenthal, 1976: Instability of finite difference schemes due to boundary conditions in elastic media. Geophys. Prospect., 24, 431-453, doi: 10.1111/ j.1365-2478.1976.tb00947.x. [Link]

Kase, Y. and K. Kuge, 1998: Numerical simulation of spontaneous rupture processes on two non-coplanar faults: The effect of geometry on fault interaction. Geophys. J. Int., 135, 911-922, doi: 10.1046/j.1365-
246X.1998.00672.x. [Link]

Kase, Y. and K. Kuge, 2001: Rupture propagation beyond fault discontinuities: Significance of fault strike and location. Geophys. J. Int., 147, 330-342, doi: 10.1046/ j.1365-246X.2001.00533.x. [Link]

Kelly, K. R., R. W. Ward, S. Treitel, and R. M. Alford, 1976: Synthetic seismograms: A finite-difference approach. Geophysics, 41, 2-27, doi: 10.1190/1.1440605. [Link]

King, G. C. P. and M. Cocco, 2001: Fault interaction by elastic stress changes: New clues from earthquake sequences. Adv. Geophys., 44, 1-38, doi: 10.1016/S00652687(00)80006-0. [Link]

Lee, Y. H., M. L. Hsieh, S. D. Lu, T. S. Shih, W. Y. Wu, Y. Sugiyama, T. Azuma, and Y. Kariya, 2003: Slip vectors of the surface rupture of the 1999 Chi-Chi earthquake, western Taiwan. J. Struct. Geol., 25, 1917-1931, doi: 10.1016/S0191-8141(03)00039-7. [Link]

Lee, Y. H., Y. C. Chen, C. L. Chen, R. J. Rau, H. C. Chen, W . Lo, and K. C. Cheng, 2011: Revealing coseismic displacement and displacement partitioning at the northern end of the 1999 Chi-Chi earthquake, central Taiwan, using digital cadastral data. Bull. Seismol. Soc. Am., 101, 1199-1212, doi: 10.1785/0120100156. [Link]

Lin, C. W., H. C. Chang, S. T. Lu, T. S. Shih, and W. J. Huang, 2000: Active fault map of Taiwan, $2^{\text {nd }}$ ed. Central Geological Survey, Ministry of Economic Affairs, Taiwan.

Lin, J. and R. S. Stein, 2004: Stress triggering in thrust and subduction earthquakes and stress interaction between the southern San Andreas and nearby thrust and strike-slip faults. J. Geophys. Res., 109, B02302, doi: 10.1029/2003JB002607. [Link]

Lindh, A. G. and D. M. Boore, 1981: Control of rupture by fault geometry during the 1966 Parkfield earthquake. Bull. Seismol. Soc. Am., 71, 95-116.

Ma, K. F., C. H. Chan, and R. S. Stein, 2005: Response of seismicity to Coulomb stress triggers and shadows of the $1999 \mathrm{M}_{\mathrm{w}}=7.6 \mathrm{Chi}-\mathrm{Chi}$, Taiwan, earthquake.J.Geophys. Res., 110, B05S 19, doi: 10.1029/2004JB003389. [Link]

Ma, K. F., C. T. Lee, Y. B. Tsai, T. C. Shin, and J. Mori, 1999: The Chi-Chi, Taiwan earthquake: Large surface displacements on an inland thrust fault. Eos, Trans., $A G U, \mathbf{8 0}, 605-611$, doi: 10.1029/99EO00405. [Link]

Madariaga, R., K. Olsen, and R. Archuleta, 1998: Modeling dynamic rupture in a 3D earthquake fault model. Bull. Seismol. Soc. Am., 88, 1182-1197.

Mikumo, T., K. Hirahara, and T. Miyatake, 1987: Dynamical fault rupture processes in heterogeneous media. Tectonophysics, 144, 19-36, doi: 10.1016/0040-1951 (87)90006-0. [Link]

Miyamura, S., 1985: The Hsinchu-Taichung, Taiwan, earthquake of April 20, 1935, Proc. Seminar Commem. 
$50^{\text {th }}$ Anniv. for Hsinchu-Taichung Earthquake of 1935, 18-44.

Miyatake, T., 1980: Numerical simulations of earthquake source process by a three-dimensional crack model. Part I. Rupture process. J. Phys. Earth, 28, 565-598, doi: 10.4294/jpe1952.28.565. [Link]

Mozziconacci, L., J. Angelier, B. Delouis, R. J. Rau, N. Béthoux, and B. S. Huang, 2009: Focal mechanisms and seismotectonic stress in North Central Taiwan in relation with the Chi-Chi earthquake. Tectonophysics, 466, 409-426, doi : 10.1016/j.tecto.2007.11.003. [Link]

Mozziconacci, L., B. Delouis, B. S. Huang, J. C. Lee and N. Béthoux, 2013: Determining fault geometry from the distribution of coseismic fault slip related to the 2006 Taitung earthquake, Eastern Taiwan. Bull.Seismol.Soc. Am., 103, 394-411, doi: 10.1785/0120110232. [Link]

Olsen, K. B., R. Madariaga, and R. J. Archuleta, 1997: Three-dimensional dynamic simulation of the 1992 Landers earthquake. Science, 278, 834-838, doi: 10.1126/science.278.5339.834. [Link]

Press, W. H., B. P. Flannery, S. A. Teukolsky, and W. T. Vetterling, 1992: Numerical Recipes in Fortran 77: The Art of Scientific Computing, Cambridge University Press, Cambridge, United Kingdom.

Scholz, C. H., 1990: The Mechanics of Earthquakes and Faulting, Cambridge University Press, Cambridge, United Kingdom.

Wang, J. C., 2005: Studies on precursory of seismicity and thrust fault interaction. Ph.D. Thesis, National Chung Cheng University, Chiayi, Taiwan, R.O.C., 108 pp.

Wang, J. C., C. F. Shieh, and T. M. Chang, 2003: Static stress changes as a triggering mechanism of a shallow earthquake: Case study of the 1999 Chi-Chi (Taiwan) earthquake. Phys. Earth Planet. In., 135, 17-25, doi: 10.1016/S0031-9201(02)00175-9. [Link]

Wang, J. C., J. H. Wang, C. F. Shieh, and Y. H. Yeh, 2010: Static stress transfer between the Chinshan and Shanchiao faults in the Taipei metropolitan area. Terr. Atmos. Ocean. Sci., 21, 515-527, doi: 10.3319/TAO. 2009.11.24.01(TH). [Link]

Wang, J. H., 1996: Velocity-weakening friction as a factor in controlling the frequency-magnitude relation of earthquakes. Bull. Seismol. Soc. Am., 86, 701-713.

Wang, J. H., 1998: Studies of earthquake seismology in Taiwan during the 1897-1996 period. J. Geol. Soc. China, 41, 291-336.

Wang, J.H., 2008: Urban seismology in the Taipei metropolitan area: Review and prospective. Terr. Atmos. Ocean. Sci., 19, 213-233, doi: 10.3319/TAO.2008.19.3.213(T). [Link]

Wang, J. H., 2012: Some intrinsic properties of the twodimensional dynamical spring-slider model of earthquake faults. Bull. Seismol. Soc. Am., 102, 822-835, doi: 10.1785/0120110172. [Link]
Wang, W. H. and C. H. Chen, 2001: Static stress transferred by the 1999 Chi-Chi, Taiwan earthquake: Effects on the stability of the surrounding fault systems and aftershock triggering with a 3-D fault slip model. Bull. Seismol. Soc. Am., 91, 1041-1052.

Wells, D. L. and K. J. Coppersmith, 1994: New empirical relationships among magnitude, rupture length, rupture width, rupture area, and surface displacement. Bull. Seismol. Soc. Am., 84, 974-1002.

Yamashita, T. and Y. Umeda, 1994: Earthquake rupture complexity due to dynamic nucleation and interaction of subsidiary faults. Pure Appl. Geophys., 143, 89-116, doi: 10.1007/BF00874325. [Link]

\section{APPENDIX}

Here, the equations of normal stress $\left(\sigma_{z^{\prime} z^{\prime}}\right)$ and displacement $\left(u_{z}^{\prime}\right)$ on the M-fault are derived in detail. In the F-coordinate, the M-fault is on the $\mathrm{X}^{\prime}-\mathrm{Y}^{\prime}$ plane, and $\mathrm{Z}^{\prime}$ is the normal direction. Taking the Taylor expansion of $u_{z^{\prime}}(i, j, k+1, t)$ in the $\mathrm{Z}^{\prime}$-direction leads to:

$u_{z^{\prime}}(k+1) \approx u_{z^{\prime}}^{+}(k)+\frac{\partial u_{z^{\prime}}^{+}}{\partial z^{\prime}}\left(\Delta z^{\prime}\right)+\frac{1}{2} \frac{\partial^{2} u_{z^{\prime}}^{+}}{\partial z^{\prime 2}}\left(\Delta z^{\prime}\right)^{2}$

It is rewritten as:

$\frac{\partial u_{z^{\prime}}^{+}}{\partial z^{\prime}}=\frac{u_{z^{\prime}}(k+1)-u_{z^{\prime}}^{+}(k)}{\Delta z^{\prime}}-\frac{\Delta z^{\prime}}{2} \frac{\partial^{2} u_{z^{\prime}}^{+}}{\partial z^{\prime 2}}$

Considering the $\mathrm{Z}^{\prime}$-component in Eq. (1), we have

$$
\begin{aligned}
\rho \frac{\partial^{2} u_{z}^{+}}{\partial t^{2}}= & \mu\left(\frac{\partial^{2} u_{z}^{+}}{\partial x^{\prime 2}}+\frac{\partial^{2} u_{z}^{+}}{\partial y^{\prime 2}}\right)+(\lambda+2 \mu) \frac{\partial^{2} u_{z}^{+}}{\partial z^{\prime 2}} \\
& +(\lambda+\mu)\left(\frac{\partial^{2} u_{x^{\prime}}^{+}}{\partial x^{\prime} \partial z^{\prime}}+\frac{\partial^{2} u_{y^{\prime}}^{+}}{\partial y^{\prime} \partial z^{\prime}}\right)
\end{aligned}
$$

and it is rewritten as:

$\frac{\partial^{2} u_{z}^{+}}{\partial z^{\prime 2}}=\frac{1}{\lambda+2 \mu}\left[\begin{array}{c}\rho \frac{\partial^{2} u_{z}^{+}}{\partial t^{2}}-\mu\left(\frac{\partial^{2} u_{z}^{+}}{\partial x^{\prime 2}}+\frac{\partial^{2} u_{z}^{+}}{\partial y^{\prime 2}}\right) \\ -(\lambda+\mu)\left(\frac{\partial^{2} u_{x^{\prime}}^{+}}{\partial x^{\prime} \partial z^{\prime}}+\frac{\partial^{2} u_{y^{\prime}}^{+}}{\partial y^{\prime} \partial z^{\prime}}\right)\end{array}\right]$

The normal stress on the hanging wall of the M-fault is:

$$
\sigma_{z^{\prime} z^{\prime}}^{+}=\lambda \frac{\partial u_{x^{\prime}}^{+}}{\partial x^{\prime}}+\lambda \frac{\partial u_{y^{\prime}}^{+}}{\partial y^{\prime}}+(\lambda+2 \mu) \frac{\partial u_{z}^{+}}{\partial z^{\prime}}
$$

Substituting Eqs. (A2) and (A4) into Eq. (A5) gives 


$$
\begin{aligned}
\sigma_{z z^{\prime}}^{+} & =(\lambda+2 \mu) \frac{u_{z^{\prime}}(k+1)-u_{z^{\prime}}^{+}(k)}{\Delta z} \\
& -\frac{\Delta z^{\prime}}{2}\left[\begin{array}{c}
\rho \frac{\partial^{2} u_{z}^{+}}{\partial t^{2}}-\mu\left(\frac{\partial^{2} u_{z}^{+}}{\partial x^{\prime 2}}+\frac{\partial^{2} u_{z}^{+}}{\partial y^{\prime 2}}\right) \\
-(\lambda+\mu)\left(\frac{\partial^{2} u_{x^{\prime}}^{+}}{\partial x^{\prime} \partial z^{\prime}}+\frac{\partial^{2} u_{y}^{+}}{\partial y^{\prime} \partial z^{\prime}}\right)
\end{array}\right] \\
+ & \lambda\left(\frac{u_{x^{\prime}}^{+}(i+1)-u_{x^{\prime}}^{+}(i-1)}{2 d x^{\prime}}+\frac{u_{y^{\prime}}^{+}(j+1)-u_{y^{\prime}}^{+}(j-1)}{2 d y^{\prime}}\right)
\end{aligned}
$$

The same operation performed for the normal stress on the footwall leads to

$$
\begin{aligned}
\sigma_{z z^{\prime}}^{-} & =(\lambda+2 \mu) \frac{u_{z}^{\prime}(k)-u_{z^{\prime}}(k-1)}{\Delta z^{\prime}} \\
& +\frac{\Delta z^{\prime}}{2}\left[\begin{array}{l}
\rho \frac{\partial^{2} u_{z}^{\prime}}{\partial t^{2}}-\mu\left(\frac{\partial^{2} u_{z}^{\prime}}{\partial x^{\prime 2}}+\frac{\partial^{2} u_{z^{\prime}}}{\partial y^{2}}\right) \\
-(\lambda+\mu)\left(\frac{\partial^{2} u_{x^{\prime}}}{\partial x^{\prime} \partial z^{\prime}}+\frac{\partial^{2} u_{y^{\prime}}}{\partial y^{\prime} \partial z^{\prime}}\right)
\end{array}\right] \\
& +\lambda\left(\frac{u_{x^{\prime}}^{\prime}(i+1)-u_{x^{\prime}}(i-1)}{2 d x^{\prime}}+\frac{u_{y^{\prime}}(j+1)-u_{y^{\prime}}(j-1)}{2 d y^{\prime}}\right)
\end{aligned}
$$

By performing $[(\mathrm{A} 6)+(\mathrm{A} 7)] / 2$, the normal stress on the $\mathrm{M}-$ fault is:

$$
\begin{aligned}
\sigma_{z^{\prime} z^{\prime}} & =(\lambda+2 \mu) \frac{u_{z^{\prime}}(k+1)-u_{z^{\prime}}(k-1)}{2 d z^{\prime}} \\
& +\frac{\Delta z^{\prime}}{4}(\lambda+\mu)\left[\left(\frac{\partial^{2} u_{x^{\prime}}^{+}}{\partial x^{\prime} \partial z^{\prime}}+\frac{\partial^{2} u_{y^{\prime}}^{+}}{\partial y^{\prime} \partial z^{\prime}}\right)-\left(\frac{\partial^{2} u_{x^{\prime}}^{-}}{\partial x^{\prime} \partial z^{\prime}}+\frac{\partial^{2} u_{y^{\prime}}}{\partial y^{\prime} \partial z^{\prime}}\right)\right] \\
& +\frac{\lambda}{2}\left(\frac{u_{x^{\prime}}^{+}(i+1)-u_{x^{\prime}}^{+}(i-1)}{2 d x^{\prime}}+\frac{u_{x^{\prime}}^{-}(i+1)-u_{x^{\prime}}^{-}(i-1)}{2 d x^{\prime}}\right) \\
& +\frac{\lambda}{2}\left(\frac{u_{y^{\prime}}^{+}(j+1)-u_{y^{\prime}}^{+}(j-1)}{2 d y^{\prime}}+\frac{u_{y^{\prime}}^{-}(j+1)-u_{y^{\prime}}^{-}(j-1)}{2 d y^{\prime}}\right)
\end{aligned}
$$

In this model, the M-fault is on the $\mathrm{X}^{\prime}-\mathrm{Y}^{\prime}$ plane. When a rupture occurs, there are two components of stress drop changes, i.e., $\Delta \sigma_{z^{\prime} x^{\prime}}$ and $\Delta \sigma_{z^{\prime} y^{\prime}}$. From Eqs. (10a) to $(10 \mathrm{c})$, the boundary conditions are:

$$
\begin{gathered}
\sigma_{z x^{\prime}}=\mu \frac{\partial u_{z^{\prime}}}{\partial x^{\prime}}+\mu \frac{\partial u_{x^{\prime}}}{\partial z^{\prime}}=\left\{\begin{array}{cl}
\Delta \sigma_{z^{\prime} x^{\prime}} & \text { cracked grids } \\
0 & \text { un-cracked grids }
\end{array}\right. \\
\sigma_{z y^{\prime}}=\mu \frac{\partial u_{z^{\prime}}}{\partial y^{\prime}}+\mu \frac{\partial u_{y^{\prime}}}{\partial z^{\prime}}=\left\{\begin{array}{cc}
\Delta \sigma_{z^{\prime} y^{\prime}} & \text { cracked grids } \\
0 & \text { un-cracked grids }
\end{array}\right.
\end{gathered}
$$

$\sigma_{z^{\prime} z^{\prime}}=\lambda \frac{\partial u_{x^{\prime}}}{\partial x^{\prime}}+\lambda \frac{\partial u_{y^{\prime}}}{\partial y^{\prime}}+(\lambda+2 \mu) \frac{\partial u_{z^{\prime}}}{\partial z^{\prime}}=0$

For an un-cracked grid, the displacement at the grid point on the hanging wall is $u_{x}^{+}(i, j, k, t)$. The $\mathrm{X}^{\prime}$-component of Eq. (1) is:

$$
\begin{aligned}
\rho \frac{\partial^{2} u_{x^{\prime}}^{+}}{\partial t^{2}} & =(\lambda+2 \mu) \frac{\partial^{2} u_{x^{\prime}}^{+}}{\partial x^{\prime 2}}+\mu\left(\frac{\partial^{2} u_{x^{\prime}}^{+}}{\partial y^{\prime 2}}+\frac{\partial^{2} u_{x^{\prime}}^{+}}{\partial z^{\prime 2}}\right) \\
& +(\lambda+\mu)\left(\frac{\partial^{2} u_{y^{\prime}}^{+}}{\partial x^{\prime} \partial y^{\prime}}+\frac{\partial^{2} u_{z}^{+}}{\partial x^{\prime} \partial z^{\prime}}\right)
\end{aligned}
$$

Therefore, we have

$$
\frac{\partial^{2} u_{x^{\prime}}^{+}}{\partial z^{\prime 2}}=\frac{1}{\mu}\left[\begin{array}{l}
\rho \frac{\partial^{2} u_{x^{\prime}}^{+}}{\partial t^{2}}-(\lambda+2 \mu) \frac{\partial^{2} u_{x^{\prime}}^{+}}{\partial x^{\prime 2}}-\mu \frac{\partial^{2} u_{x^{\prime}}^{+}}{\partial y^{\prime 2}} \\
-(\lambda+\mu)\left(\frac{\partial^{2} u_{y^{\prime}}^{+}}{\partial x^{\prime} \partial y^{\prime}}+\frac{\partial^{2} u_{z^{\prime}}^{+}}{\partial x^{\prime} \partial z^{\prime}}\right)
\end{array}\right]
$$

Rewriting Eq. (A9) for the un-cracked grid leads to

$$
\frac{\partial u_{x}^{+}}{\partial z}=-\frac{\partial u_{z}^{+}}{\partial x}
$$

The Taylor expansion of $u_{x^{\prime}}(i, j, k+1, t)$ in the $Z^{\prime}$-direction is:

$u_{x^{\prime}}(k+1) \approx u_{x^{\prime}}^{+}(k)+\frac{\partial u_{x^{\prime}}^{+}}{\partial z^{\prime}}\left(\Delta z^{\prime}\right)+\frac{1}{2} \frac{\partial^{2} u_{x^{\prime}}^{+}}{\partial z^{2}}\left(\Delta z^{\prime}\right)^{2}$

Substituting Eqs. (A13) and (A14) into Eq. (A15) gives

$$
\begin{aligned}
u_{x^{\prime}}(k+1) \approx & u_{x^{\prime}}^{+}(k)-\frac{\partial u_{z^{\prime}}^{+}}{\partial x^{\prime}}\left(\Delta z^{\prime}\right)+\frac{1}{2 \mu} \\
& {\left[\begin{array}{l}
\rho \frac{\partial^{2} u_{x^{\prime}}^{+}}{\partial t^{2}}-(\lambda+2 \mu) \frac{\partial^{2} u_{x^{\prime}}^{+}}{\partial x^{\prime 2}}-\mu \frac{\partial^{2} u_{x^{\prime}}^{+}}{\partial y^{\prime 2}} \\
-(\lambda+\mu)\left(\frac{\partial^{2} u_{y^{\prime}}^{+}}{\partial x^{\prime} \partial y^{\prime}}+\frac{\partial^{2} u_{z^{\prime}}^{+}}{\partial x^{\prime} \partial z^{\prime}}\right)
\end{array}\right]\left(\Delta z^{\prime}\right)^{2} }
\end{aligned}
$$

Therefore, we have

$$
\begin{array}{r}
\frac{2 \mu}{\Delta z^{\prime}}\left[\frac{u_{x^{\prime}}(k+1)-u_{x^{\prime}}^{+}(k)}{\Delta z^{\prime}}+\frac{\partial u_{z}^{+}}{\partial x^{\prime}}\right]=\rho \frac{\partial^{2} u_{x^{\prime}}^{+}}{\partial t^{2}}-(\lambda+2 \mu) \\
\cdot \frac{\partial^{2} u_{x^{\prime}}^{+}}{\partial x^{\prime 2}}-\mu \frac{\partial^{2} u_{x^{\prime}}^{+}}{\partial y^{\prime 2}}-(\lambda+\mu)\left(\frac{\partial^{2} u_{y^{\prime}}^{+}}{\partial x^{\prime} \partial y^{\prime}}+\frac{\partial^{2} u_{z}^{+}}{\partial x^{\prime} \partial z^{\prime}}\right)
\end{array}
$$

From a similar derivation, the displacement at the grid point on the footwall, i.e., $u_{x^{\prime}}(i, j, k, t)$, is: 


$$
\begin{array}{r}
\frac{2 \mu}{\Delta z^{\prime}}\left[\frac{u_{x^{\prime}}(k-1)-u_{x^{\prime}}^{\prime}(k)}{\Delta z^{\prime}}+\frac{\partial u_{z^{\prime}}^{\prime}}{\partial x^{\prime}}\right]=\rho \frac{\partial^{2} u_{x^{\prime}}^{\prime}}{\partial t^{2}}-(\lambda+2 \mu) \\
\cdot \frac{\partial^{2} u_{x^{\prime}}}{\partial x^{\prime 2}}-\mu \frac{\partial^{2} u_{x^{\prime}}^{\prime}}{\partial y^{\prime 2}}-(\lambda+\mu)\left(\frac{\partial^{2} u_{y^{\prime}}^{\prime}}{\partial x^{\prime} \partial y^{\prime}}+\frac{\partial^{2} u_{z^{\prime}}^{\prime}}{\partial x^{\prime} \partial z^{\prime}}\right)
\end{array}
$$

By performing $[(\mathrm{A} 17)+(\mathrm{A} 18)] / 2$, the equation of motion at an un-cracked grid obtained from Eq. (A19) and used to calculate displacement, $u_{x^{\prime}}$, is:

$$
\begin{aligned}
\rho \frac{\partial^{2} u_{x^{\prime}}}{\partial t^{2}}= & \frac{\lambda+2 \mu}{2} \frac{\partial^{2}\left(u_{x^{+}}^{+}+u_{x^{-}}^{-}\right)}{\partial x^{\prime}{ }^{2}}+\frac{\mu}{2} \frac{\partial^{2}\left(u_{x^{\prime}}^{+}+u_{x^{\prime}}^{-}\right)}{\partial y^{\prime 2}}+\mu \frac{\partial^{2} u_{x^{\prime}}}{\partial z^{\prime 2}} \\
& +\frac{(\lambda+\mu)}{2} \frac{\partial^{2}\left(u_{y^{\prime}}^{+}+u_{y^{-}}\right)}{\partial x^{\prime} \partial y^{\prime}}+(\lambda+\mu) \frac{\partial^{2} u_{z}}{\partial x^{\prime} \partial z^{\prime}}
\end{aligned}
$$

For a cracked grid, the displacement at the grid point on the handing wall is $u_{x}^{+}(i, j, k, t)$. From Eq. (A9), the boundary condition is:

$\sigma_{z^{\prime} x^{\prime}}^{+}=\mu \frac{\partial u_{z}^{+}}{\partial x^{\prime}}+\mu \frac{\partial u_{x^{\prime}}^{+}}{\partial z^{\prime}}=\Delta \sigma_{z^{\prime} x^{\prime}}$

Therefore, we have

$\frac{\partial u_{x^{\prime}}^{+}}{\partial z^{\prime}}=\frac{\Delta \sigma_{z x^{\prime}}}{\mu}-\frac{\partial u_{z}^{+}}{\partial x^{\prime}}$
Similar operations as from Eq. (A15) to Eq. (A17), the equation for a cracked grid is:

$$
\begin{gathered}
\frac{2 \mu}{\Delta z^{\prime}}\left[\frac{u_{x^{\prime}}(k+1)-u_{x^{\prime}}^{+}(k)}{\Delta z^{\prime}}+\frac{\partial u_{z}^{+}}{\partial x^{\prime}}-\frac{\Delta \sigma_{z^{\prime} x^{\prime}}}{\mu}\right] \\
=\rho \frac{\partial^{2} u_{x^{\prime}}^{+}}{\partial t^{2}}-(\lambda+2 \mu) \frac{\partial^{2} u_{x^{\prime}}^{+}}{\partial x^{\prime 2}}-\mu \frac{\partial^{2} u_{x^{\prime}}^{+}}{\partial y^{\prime 2}} \\
-(\lambda+\mu)\left(\frac{\partial^{2} u_{y^{\prime}}^{+}}{\partial x^{\prime} \partial y^{\prime}}+\frac{\partial^{2} u_{z}^{+}}{\partial x^{\prime} \partial z^{\prime}}\right)
\end{gathered}
$$

Hence, the equation of motion for a cracked grid on the hanging wall is:

$$
\begin{aligned}
\rho \frac{\partial^{2} u_{x^{\prime}}^{+}}{\partial t^{2}} & =(\lambda+2 \mu) \frac{\partial^{2} u_{x^{\prime}}^{+}}{\partial x^{\prime 2}}+\mu \frac{\partial^{2} u_{x^{\prime}}^{+}}{\partial y^{\prime 2}} \\
& +(\lambda+\mu)\left(\frac{\partial^{2} u_{y^{\prime}}^{+}}{\partial x^{\prime} \partial y^{\prime}}+\frac{\partial^{2} u_{z}^{+}}{\partial x^{\prime} \partial z^{\prime}}\right)+\frac{2}{\Delta z^{\prime}}\left(\sigma_{z x^{\prime}}^{+}-\Delta \sigma_{z x^{\prime}}\right)
\end{aligned}
$$

From similar derivation, the equation of motion at the cracked grid on the footwall is:

$$
\begin{aligned}
\rho \frac{\partial^{2} u_{x^{\prime}}}{\partial t^{2}} & =(\lambda+2 \mu) \frac{\partial^{2} u_{x^{\prime}}^{\prime}}{\partial x^{\prime 2}}+\mu \frac{\partial^{2} u_{x^{\prime}}}{\partial y^{\prime 2}} \\
& +(\lambda+\mu)\left(\frac{\partial^{2} u_{y^{\prime}}}{\partial x^{\prime} \partial y^{\prime}}+\frac{\partial^{2} u_{z^{\prime}}^{\prime}}{\partial x^{\prime} \partial z^{\prime}}\right)-\frac{2}{\Delta z^{\prime}}\left(\sigma_{z^{\prime} x^{\prime}}^{-}-\Delta \sigma_{z^{\prime} x^{\prime}}\right)
\end{aligned}
$$

